\title{
Connexins and Pannexins: New Insights into Microglial Functions and Dysfunctions
}

\author{
Rosario Gajardo-Gómez, Valeria C. Labra and Juan A. Orellana* \\ Departamento de Neurología, Escuela de Medicina, Pontificia Universidad Católica de Chile, Santiago, Chile
}

Under physiological conditions, microglia adopt a resting phenotype associated with the production of anti-inflammatory and neurotrophic factors. In response to a wide variety of insults, these cells shift to an activated phenotype that is necessary for the proper restoration of brain homeostasis. However, when the intensity of a threat is relatively high, microglial activation worsens the progression of damage rather than providing protection, with potentially significant consequences for neuronal survival. Coordinated interactions among microglia and other brain cells, including astrocytes and neurons, are critical for the development of timely and optimal inflammatory responses in the brain parenchyma. Tissue synchronization is in part mediated by connexins and pannexins, which are protein families that form different plasma membrane channels to communicate with neighboring cells. Gap junction channels (which are exclusively formed by connexins in vertebrates) connect the cytoplasm of contacting cells to

OPEN ACCESS

Edited by: Ildikó Rácz, University of Bonn, Germany

Reviewed by: Björn Spittau, University of Freiburg, Germany Samaneh Maysami, University of Manchester, UK Juan Pablo De Rivero Vaccari, University of Miami, USA

*Correspondence: Juan A. Orellana jaorella@uc.cl

Received: 15 June 2016 Accepted: 05 September 2016 Published: 22 September 2016

Citation: Gajardo-Gómez R, Labra VC and Orellana JA (2016) Connexins and

Pannexins: New Insights into Microglial Functions and Dysfunctions.

Front. Mol. Neurosci. 9:86 doi: 10.3389/fnmol.2016.00086 coordinate electrical and metabolic coupling. Hemichannels (HCs) and pannexons (which are formed by connexins and pannexins, respectively) communicate the intraand extracellular compartments and serve as diffusion pathways for the exchange of ions and small molecules. In this review article, we discuss the available evidence concerning the functional expression and regulation of connexin- and pannexin-based channels in microglia and their contributions to microglial function and dysfunction. Specifically, we focus on the possible implications of these channels in microglia-to-microglia, microgliato-astrocyte and neuron-to-microglia interactions in the inflamed brain.

Keywords: microglia, hemichannels, gap junctions, pannexons, brain, gliotransmitters

\section{BACKGROUND}

Microglia constitute approximately $5-15 \%$ of total cells in the central nervous system (CNS) and are the major components of the innate immune system in the brain (Lawson et al., 1990). Originating from myelomonocytic precursor cells (i.e., fetal macrophages) derived from the hemangioblastic mesoderm, microglia populate the brain parenchyma prior to the developmental closure of the blood-brain barrier (BBB; Ginhoux et al., 2010). Under physiological conditions, microglia exhibit a "resting" surveillance state (ramified morphology) that is associated with active environmental exploration and the continuous search for exogenous or endogenous signals representing a brain threat (Streit, 2001; Kettenmann et al., 2011). Microglia assume protagonistic roles that extend far beyond their classic participation in inflammatory and immunological responses, such as the control of 
neuronal proliferation and differentiation and synaptic plasticity and transmission ( $\mathrm{Wu}$ et al., 2015). In particular, the fine interactions between microglia and chemical synapses are essential for the consolidation of neuronal circuits, thereby expanding the current concept of the "tripartite synapse" into a "quad-partite synapse" (Schafer et al., 2013; Wake et al., 2013).

Once homeostatic balance is altered, the resting microglia phenotype shifts to a reactive phenotype (phagocytic morphology) involving alterations to different microglial functions, such as proliferation, morphology, motility and migration, proteostasis, phagocytosis and intercellular communication (Hanisch, 2002; Block et al., 2007). This wide array of changes is known as "microglial activation" and involves large-scale and substantial activation depending on the nature, intensity and duration of the stimulus (Ransohoff and El Khoury, 2015). During intense challenges and chronic brain damage, microglia become uncontrolled sources of inflammatory mediators (e.g., cytokines and free radicals) that cause neuronal damage rather than exhibiting a repair-orientated activity profile (Block et al., 2007). Although an efficient immune response is necessary to resolve brain threats, under these circumstances, dysfunctional microglia favor the recruitment of non-resident brain cells involved in the innate and adaptive immune responses, thereby intensifying brain injury (Waisman et al., 2015).

\section{GENERAL CONCEPTS CONCERNING CONNEXINS AND PANNEXINS}

Transitions and commitments towards distinct reactive phenotypes require close synchronization and communication among microglia (Salter and Beggs, 2014). In vertebrates, cellto-cell communication and coordination between neighboring cells are in part mediated by gap junctions (Bennett et al., 1991; Sáez et al., 2003). Gap junctions are aggregates of intercellular channels termed gap junction channels (GJCs) that facilitate direct but selective cytoplasmic continuity between contacting cells to promote the exchange of ions (allowing electrical coupling), metabolites (e.g., adenosine diphosphate $[\mathrm{ADP}]$, glucose, lactate and glutamate) and second messengers (e.g., cyclic adenosine monophosphate [CAMP] and inositol trisphosphate [ $\left.\mathrm{IP}_{3}\right]$; Söhl et al., 2005; Goodenough and Paul, 2009; Figure 1). A GJC comprises the serial docking of two hemichannels (HCs), one of each contributed by two adjacent cells. Each HC consists of a six-fold ring of connexin monomers; thus, these channels are also known as connexons (Figure 1). Connexins are members of a highly conserved protein family encoded by 21 genes in humans and 20 genes in mice with orthologs in other vertebrate species (Abascal and Zardoya, 2012).

Although they have long been recognized as the building blocks of GJCs, HCs are fundamental pathways for molecular and ionic interchange between intracellular and extracellular compartments (Sáez and Leybaert, 2014). In a pioneering study by Paul et al. (1991), cytoplasmic injection of Xenopus oocytes with connexin46 (Cx46) mRNA (a newly cloned member of the connexin family at the time) caused the induction of nonselective cation currents, depolarization and cell lysis in single oocytes. This phenomenon was not observed after transfection with other connexins, leading to the following rationale: open HCs disturb ionic imbalance, resulting in the persistent loss of membrane potential and subsequent cell death. Therefore, $\mathrm{HC}$ openings were assumed to be incompatible with normal cell life. However, this concept has been disproven in the last two decades by groundbreaking findings (Cotrina et al., 1998; Stout et al., 2002; Ye et al., 2003; Cherian et al., 2005; Romanov et al., 2007; Tong et al., 2007; Anselmi et al., 2008; Burra et al., 2010; Garré et al., 2010; Orellana et al., 2012a; Stehberg et al., 2012; Chever et al., 2014; Roux et al., 2015). According to current thinking, the physiological opening of $\mathrm{HCs}$ is required for the release of paracrine substances into the extracellular milieu (e.g., adenosine triphosphate [ATP], glutamate, nicotinamide adenine dinucleotide $\left[\mathrm{NAD}^{+}\right]$and prostaglandin $\left.\mathrm{E} 2\left[\mathrm{PGE}_{2}\right]\right)$ and the uptake of small molecules and ions up to $\sim 1-1.2 \mathrm{kDa}$ in size (e.g., glucose, cyclic ADP-ribose [cADPR] and $\mathrm{Ca}^{2+}$; Wang et al., 2013; Sáez and Leybaert, 2014; Figure 1).

A family of chordate proteins homologous to the "innexins" (the gap junction proteins of invertebrates) was discovered more than a decade ago (Panchin et al., 2000). This three-member family was designated the "pannexins" (Panx1-3) due to their ubiquitous presence in all eumetazoans with the exception of echinoderms (Abascal and Zardoya, 2012; Bond and Naus, 2014; Figure 1). Although pannexins form GJCs when overexpressed in Xenopus oocytes (Bruzzone et al., 2003), it seems that pannexins lose their ability to directly couple adjacent cells in vivo (Sosinsky et al., 2011). The major function of pannexins is form single membrane channels (the so-called pannexons) similar to HCs that permit paracrine/autocrine signaling with specific features among cells (Dahl, 2015).

In the nervous system, HCs and pannexons fulfill important physiological functions, including ischemic tolerance (Lin et al., 2008; Schock et al., 2008), the establishment of adhesive interactions (Cotrina et al., 2008), fear memory consolidation (Stehberg et al., 2012), synaptic transmission (Klaassen et al., 2011; Prochnow et al., 2012; Ardiles et al., 2014; Chever et al., 2014), electrical activity and oscillations (Moore et al., 2014; Lopatáŕ et al., 2015; Roux et al., 2015), glucose sensing (Orellana et al., 2012a), mast cell degranulation (Harcha et al., 2015), chemoreception (Wenker et al., 2012), BBB permeability (De Bock et al., 2011; Kaneko et al., 2015), colonic transit (McClain et al., 2014), migration (Liu et al., 2010, 2012) and proliferation (Wicki-Stordeur et al., 2012). In contrast, different pathological scenarios modify the normal functions of HCs and pannexons, thereby altering their opening and permeability properties and contributing to the onset and progression of diverse brain diseases (Orellana et al., 2012b, 2013a; Bosch and Kielian, 2014; Shestopalov and Slepak, 2014; Takeuchi and Suzumura, 2014; Decrock et al., 2015). Here, we review and discuss the available evidence concerning the functional expression and regulation of GJCs, HCs and pannexons in microglia and their contributions to microglial function and dysfunction (Tables 1, 2). 


\section{Connexin}

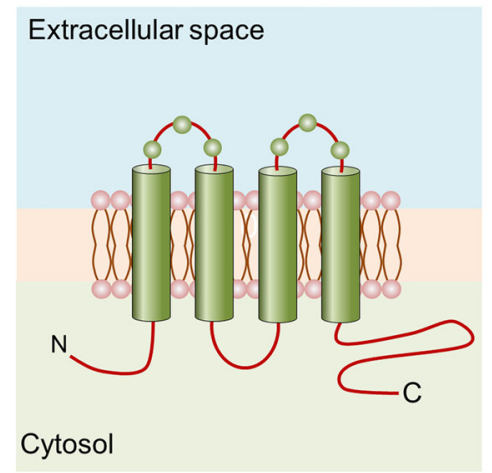

Innexin

Extracellular space

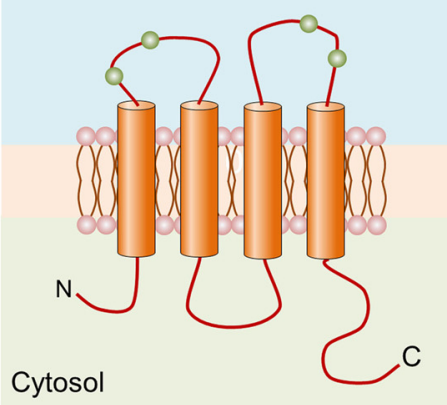

Pannexin

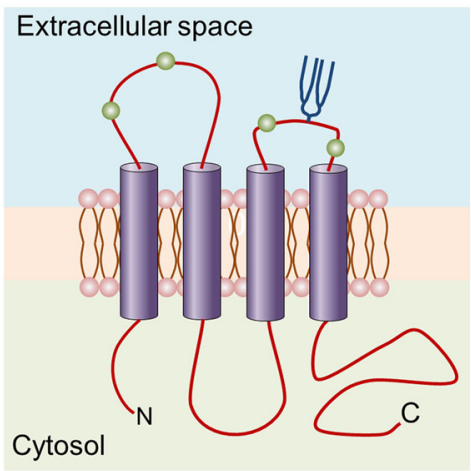

\section{Connexon Innexon Hemichannel Pannexon}

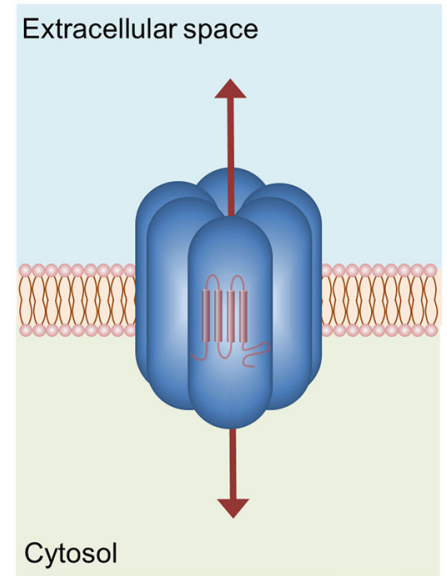

Connexon-to-Connexon Innexon-to-Innexon

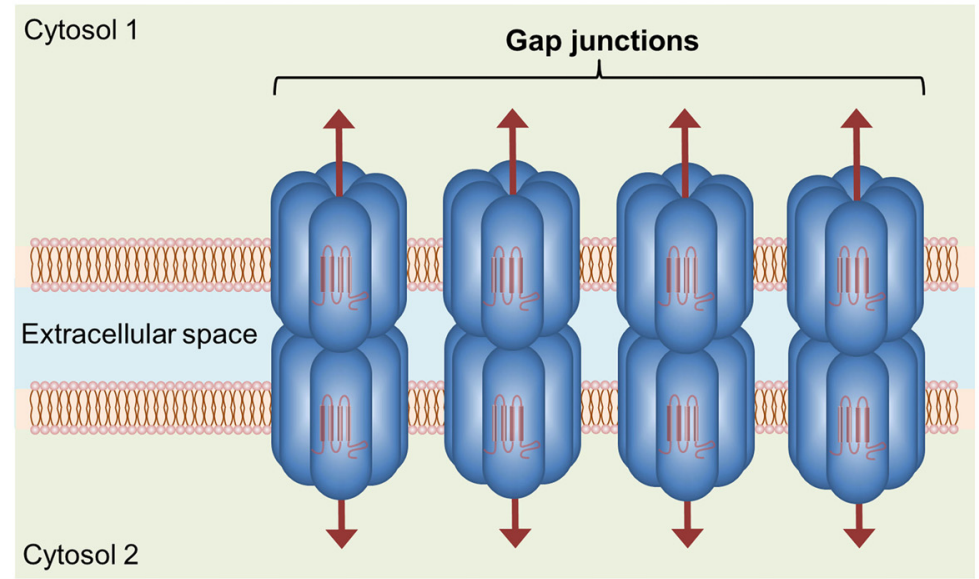

FIGURE 1 | Basic structure of channels formed by connexins, innexins and pannexins. Connexins, innexins and pannexins share similar membrane topologies consisting of four $\alpha$-helical transmembrane domains connected by two extracellular loops and one cytoplasmic loop; both the amino- and carboxy-termini are intracellular. The relative positions of the extracellular loop cysteines (green balls) and glycosylated asparagines (blue branches) are also shown. Connexons or innexons (also known as hemichannels (HCs)) are formed from connexins or innexins consisting of six subunits each. Pannexons are single membrane channels composed of six pannexin subunits. Recently, a Panx2 band pattern more consistent with an octamer than a hexamer was observed in cross-linking studies and native gels examining purified homomeric full-length and C-terminal truncation mutants (Ambrosi et al., 2010). Under resting conditions, HCs and pannexons remain preferentially closed, but they are activated by diverse physiological and pathological conditions and represent a diffuse transmembrane route between the intra- and extracellular milieu. HCs dock with one another to form functional cell-to-cell channels termed gap junction channels (GJCs). GJCs aggregate in well-known anatomical structures called gap junctions to facilitate the intercellular exchange of metabolites, second messengers and ions.

\section{GAP JUNCTION COUPLING AND ITS IMPLICATIONS FOR MICROGLIAL FUNCTIONS}

Connexin expression among microglia depends heavily on the context of their activation. Although connexin36 (Cx36) and connexin32 (Cx32) are highly expressed in the resting surveillance state (Parenti et al., 2002; Dobrenis et al., 2005; Maezawa and Jin, 2010), Cx43 protein and messenger ribonucleic acid (mRNA) expression is rarely detected under these conditions (Eugenín et al., 2001; Martínez et al., 2002; Rouach et al., 2002; Dobrenis et al., 2005; Garg et al., 2005; Hinkerohe et al., 2005, 2010; Lee et al., 2005; Même et al., 2006; Shaikh et al., 2012; Richter et al., 2014). When microglia shift from resting to activated states in different pathological scenarios, connexin expression increases, particularly connexin29 (Cx29; Moon et al., 2010), Cx32 (Takeuchi et al., 2006; Maezawa and Jin, 2010; Moon et al., 2010), Cx36 (Cepeda et al., 2015) and Cx43 (Eugenín et al., 2001; Garg et al., 2005; Orellana et al., 2011b; Eugenin et al., 2012; Sáez et al., 2013; Talaverón et al., 2014; Table 1). In the first study to demonstrate this phenomenon, reported by Eugenín et al. (2001), stab wound injury or treatment with tumor necrosis factor alpha (TNF- $\alpha$ ) plus interferon gamma (IFN- $\gamma$ ) promoted microglial activation and strongly increased $\mathrm{Cx} 43$ 
TABLE 1 | Regulation of connexin and pannexin expression in microglia.

\begin{tabular}{|c|c|c|c|c|}
\hline Effector & Protein levels & mRNA levels & Technique & Reference \\
\hline Cryotraumatic brain injury & $\uparrow \mathrm{Cx} 29 \uparrow \mathrm{Cx} 32$ & NT & Immunohistochemistry & Moon et al. (2010) \\
\hline LPS & $\uparrow \mathrm{Cx} 32$ & NT & Flow cytochemistry & Takeuchi et al. (2006) \\
\hline MeCP2 deficiency & $\uparrow \mathrm{Cx} 32$ & NE & RT-PCR, Immunohistochemistry, Western blotting & Maezawa and Jin (2010) \\
\hline TNF- $\alpha$ & $\uparrow \mathrm{C} \times 32$ & NT & Flow cytochemistry & Takeuchi et al. (2006) \\
\hline GM-CSF & NE CX36 & NT & Western blotting & Dobrenis et al. (2005) \\
\hline $\mathrm{IFN}-\gamma+\mathrm{TNF}-\alpha$ & $\uparrow \mathrm{C} \times 36$ & NT & Western blotting & Dobrenis et al. (2005) \\
\hline LPS & NT & NE CX36 & RT-PCR & Dobrenis et al. (2005) \\
\hline Rasmussen encephalitis & $\uparrow \mathrm{Cx36}$ & NT & Immunohistochemistry & Cepeda et al. (2015) \\
\hline AGEs & $\uparrow \mathrm{Cx} 43$ & NT & Western blotting & Shaikh et al. (2012) \\
\hline Amyloid $\beta$-peptide & $\uparrow \mathrm{C} \times 43$ & NT & Western blotting & Orellana et al. (2011b) \\
\hline Brain stab wound & $\uparrow \mathrm{C} \times 43$ & NT & Immunocytochemistry & Eugenín et al. (2001) \\
\hline Calcium ionophore & $\uparrow \mathrm{C} \times 43$ & $\uparrow \mathrm{Cx} 43$ & Immunohistochemistry, Western blotting, RT-PCR & Martínez et al. (2002) \\
\hline Glioma & NT & NF Cx43 & RT-PCR & Richter et al. (2014) \\
\hline GM-CSF & NF Cx43 & NT & Western blotting & Dobrenis et al. (2005) \\
\hline HIV encephalitis & $\uparrow \mathrm{C} \times 43$ & NT & Immunocytochemistry & Eugenin et al. (2012) \\
\hline LPS & NF Cx43 & NT & Western blotting, Immunohistochemistry & Même et al. (2006) \\
\hline $\mathrm{IFN}-\gamma+\mathrm{TNF}-\alpha$ & NF Cx43 & NT & Western blotting & Dobrenis et al. (2005) \\
\hline IFN- $\gamma+$ TNF- $\alpha$ & $\uparrow \mathrm{C} \times 43$ & NT & Immunocytochemistry, Western blotting & Eugenín et al. (2001) \\
\hline Peptidoglycan & $\uparrow \mathrm{C} \times 43$ & $\uparrow \mathrm{CX} 43$ & RT-PCR, Western blotting & Garg et al. (2005) \\
\hline Spinal cord injury & NE CX43 & NT & Immunohistochemistry & Lee et al. (2005) \\
\hline Restraint stress & NE CX43 & NT & Immunohistochemistry & Orellana et al. (2015) \\
\hline $\mathrm{TNF}-\alpha$ & $\uparrow \mathrm{C} \times 43$ & NT & Western blotting & Shaikh et al. (2012) \\
\hline TNF- $\alpha+$ ATP & $\uparrow \mathrm{C} \times 43$ & NT & Western blotting & Sáez et al. (2013) \\
\hline $\mathrm{TNF}-\alpha+\mathrm{IL}-1 \beta$ & $\uparrow \mathrm{Cx} 43$ & NT & Western blotting & Sáez et al. (2013) \\
\hline $\mathrm{TNF}-\alpha+\mathrm{IFN}-\gamma$ & $\uparrow \mathrm{C} \times 43$ & NT & Western blotting & Sáez et al. (2013) \\
\hline Transplantation of NPCs & $\uparrow C \times 43$ & NT & Immunohistochemistry & Talaverón et al. (2014) \\
\hline Amyloid $\beta$-peptide & $\uparrow P a n \times 1$ & NT & Western blotting & Orellana et al. (2011b) \\
\hline $\mathrm{IFN}-\gamma$ & NT & $\uparrow P a n \times 1$ & RT-PCR & Shestopalov and Slepak (2014) \\
\hline Prenatal nicotine and postnatal HFC diet & NE Panx1 & NT & Immunohistochemistry & Orellana et al. (2014) \\
\hline Restraint stress & NE Panx1 & NT & Immunohistochemistry & Orellana et al. (2015) \\
\hline Rasmussen encephalitis & $\uparrow P a n \times 1$ & NT & Immunohistochemistry & Cepeda et al. (2015) \\
\hline TNF- $\alpha+$ ATP & $\uparrow P a n \times 1$ & NT & Western blotting & Sáez et al. (2013) \\
\hline $\mathrm{TNF}-\alpha+\mathrm{IL}-1 \beta$ & $\uparrow P a n \times 1$ & NT & Western blotting & Sáez et al. (2013) \\
\hline $\mathrm{TNF}-\alpha+\mathrm{IFN}-\gamma$ & $\uparrow P a n \times 1$ & NT & Western blotting & Sáez et al. (2013) \\
\hline
\end{tabular}

NE, no effect; NT, not tested; NF, not found; LPS, lipopolysaccharide; Mecp2, methyl-CpG binding protein 2; TNF- $\alpha$, tumor necrosis factor alpha; GM-CSF, granulocytemacrophage colony-stimulating factor; IFN- $\gamma$, interferon gamma; AGEs, advanced glycation end-products; HIV, human immunodeficiency virus; ATP, adenosine triphosphate; IL-1 $\beta$, interleukin-1 beta; NPCs, neural progenitor cells; HCF, high fat/cholesterol.

expression based on immunofluorescence and western blotting analyses. Remarkably, TNF- $\alpha$ plus IFN- $\gamma$ enabled microglial communication via gap junctions based on dye coupling with Lucifer yellow (LY). This phenomenon occurs in a Cx43dependent manner because microglia cultured from Cx43 knockout (KO) mice did not exhibit GJC up-regulation following treatment with the same mixture of pro-inflammatory agents (Eugenín et al., 2001). Similar findings involving advanced glycation end-products (AGEs) and TNF- $\alpha$ were reported by Shaikh et al. (2012) AGE treatment increased Cx43 expression and the release of TNF- $\alpha$ in human microglial CHME-5 cells via a mechanism dependent on activation of the receptor for AGE (RAGE). Importantly, treatment with TNF- $\alpha$ for 6 h mimicked AGE-induced Cx43 expression, but also evoked the development of direct microglia-to-microglia coupling and HC opening. Therefore, the AGE-induced release of TNF- $\alpha$ by microglia exerted autocrine/paracrine enhanced effects on both GJC and HC functions (Shaikh et al., 2012; Table 2; Figure 2).

Microglia are rapidly activated in response to tissue damage (Davalos et al., 2005), which initiates the complex production of cytokines and gliotransmitters (e.g., ATP/ADP) that act in an autocrine/paracrine manner to specifically govern dynamic changes in the microglial phenotype (Chakfe et al., 2002; Inoue, 2002; Seo et al., 2008). Thus, these modulators are not simple on/off switches that control microglial activation but instead demonstrate synergism, cooperation and even antagonism. This phenomenon is evident in the induction of microglial coupling triggered by $\mathrm{TNF}-\alpha$, as previously mentioned (Figure 2). In a study by Sáez et al. (2013), ATP, IFN- $\gamma$ or interleukin-6 (IL-6) accelerated, delayed or prevented TNF- $\alpha$-evoked LY coupling in cultured microglia, respectively (Figure 1). Because oxidized ATP (P2X receptor blocker), 1,2-bis(o-aminophenoxy)ethane-N,N,N', $\mathrm{N}^{\prime}$-tetraacetic acid, BAPTA, $\mathrm{Ca}^{2+}$ chelator) and IL-1ra (IL-1 $\beta$ receptor antagonist) prevented microglial coupling caused by TNF- $\alpha$ plus ATP, increases in the intracellular free $\mathrm{Ca}^{2+}$ concentration $\left(\left[\mathrm{Ca}^{2+}\right]_{\mathrm{i}}\right)$ induced via the activation of $\mathrm{P} 2 \mathrm{X}$ receptors led to the autocrine release of IL-1 $\beta$ and further upregulation of GJC functions (Sáez et al., 2013; Figure 2). Consistent with this line of thought, $\mathrm{P} 2 \mathrm{X}$ receptor activation increases $\left[\mathrm{Ca}^{2+}\right]_{\mathrm{i}}$ in microglia (Ferrari et al., 1996) and promotes gap 
TABLE 2 | Regulation of connexin- and pannexin-based channels in microglia.

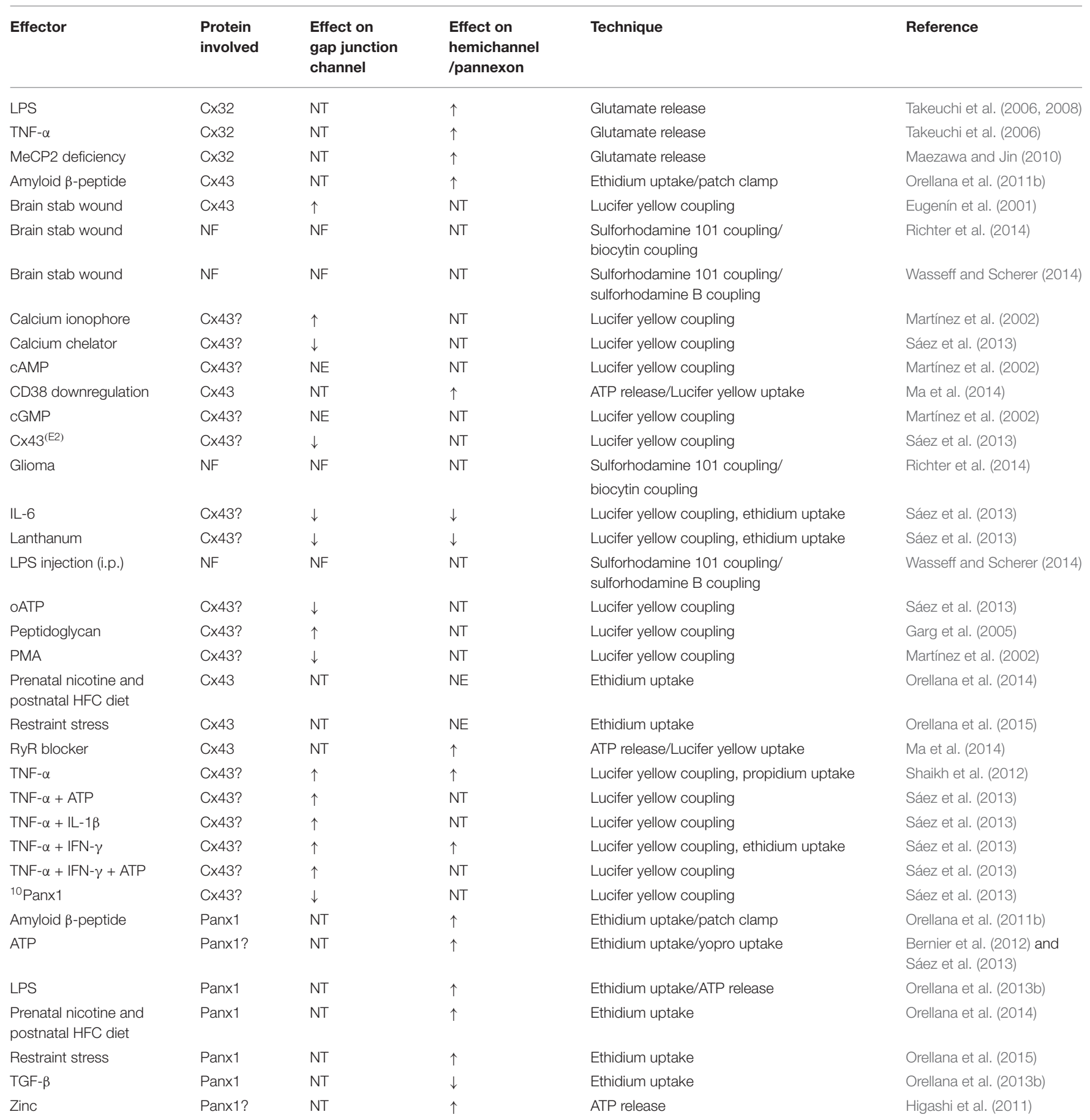

NE, no effect; NT, not tested; NF, not found; LPS, lipopolysaccharide; Mecp2, methyl-CpG binding protein 2; TNF- $\alpha$, tumor necrosis factor alpha; cAMP, cyclic adenosine monophosphate; CGMP, cyclic guanosine monophosphate; IL-6, interleukin-6; OATP, oxidized adenosine triphosphate; PMA, phorbol-12-myristate-13-acetate; RyR, ryanodine receptor; IFN- $\gamma$, interferon gamma; ATP, adenosine triphosphate; IL-1 $\beta$, interleukin-1 beta; HCF, high fat/cholesterol; TGF- $\beta$, transforming growth factor beta.

junction communication (Martínez et al., 2002). In seminal studies performed by Martínez et al. (2002), LY coupling evoked by the $\mathrm{Ca}^{2+}$ ionophore $4 \mathrm{Br}-\mathrm{A} 23187$ correlated with elevated $\mathrm{Cx} 43$ protein and mRNA levels. Although the increase in $\left[\mathrm{Ca}^{2+}\right]_{\mathrm{i}}$ is a conserved mechanism to directly inhibit gap junctions formed by several connexins (Peracchia, 2004), it is unknown whether this phenomenon is unique to microglia or the indirect result of downstream effectors of $\mathrm{Ca}^{2+}$ that regulate the sorting, synthesis and/or degradation of Cx43 GJCs. 


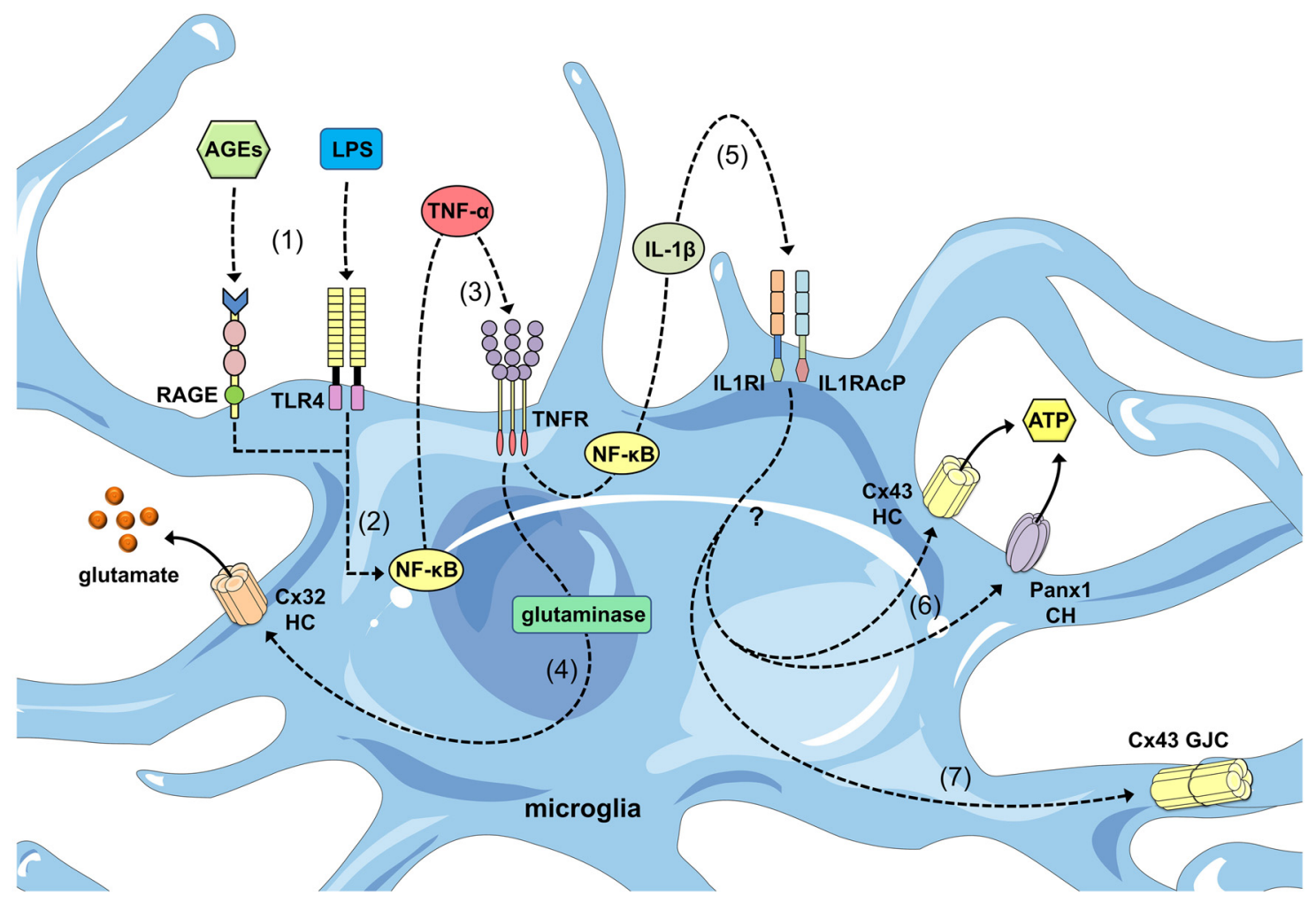

FIGURE 2 | Regulation of connexin- and pannexin-based channels by cytokines released from activated microglia. Advanced glycation end-products (AGEs) and lipopolysaccharide (LPS) stimulate the receptor for age (RAGE) and Toll-like receptor 4 (TLR4) receptors (1), respectively, resulting in activation of the nuclear factor-к $\beta$; (NF-к $\beta$ ) pathway (2). This pathway induces the autocrine/paracrine release of tumor necrosis factor- $\alpha$; (TNF- $\alpha$ ), which acts upon its receptor TNFR1 (3) and leads to the activation of glutaminase and the further release of glutamate through $\mathrm{C} \times 32 \mathrm{HCs}$ (4). In parallel, NF-к $\beta$ signaling promotes the autocrine/paracrine release of interleukin-1 $\beta$; (IL-1 $\beta$ ), which acts upon its receptor as well as accessory proteins (IL1RI and IL1RAcP; 5) and leads to the release of ATP through CX43 HCs and Panx1 channels (CHs) via an unknown mechanism (6). Additionally, IL-1 $\beta$ signaling favors the opening of GJCs composed of Cx43.

The previously described microglial coupling not only begins during cytokine treatment but is also initiated when microglia are exposed to bacteria-derived agents (Table 2). In studies in primary microglia performed a decade ago, Staphylococcus aureus-derived peptidoglycan (PGN) increased Cx43 mRNA and protein levels as measured by reverse transcription polymerase chain reaction (RT-PCR), western blotting and immunofluorescence analysis (Garg et al., 2005). Notably, Cx43 upregulation was accompanied by the gap junction-dependent spread of LY among microglia, and this response was completely blunted by $18-\alpha$-glycyrrhetinic acid, which is a well-known gap junction blocker (Garg et al., 2005). Microglial coupling triggered by PGN relies on the direct action of this molecule on pattern recognition receptors, including CD14 and Toll-like receptor 2 (TLR2). Supporting this notion, the direct activation of TLR2 upregulates $\mathrm{Cx} 43$ mRNA expression and functional communication through GJCs in intestinal epithelial cells (Ey et al., 2009). Alternatively, nuclear factor $\kappa \mathrm{B}(\mathrm{NF}-\kappa \mathrm{B})$ and mitogen-activated protein kinase (MAPK) signaling promote the autocrine/paracrine release of cytokines and inflammatory mediators following PGN-induced TLR2 activation (Akira et al., 2001), particularly TNF- $\alpha$ and
IL-1 $\beta$, which are well known inducers of gap junction functions in microglia (Eugenín et al., 2001; Shaikh et al., 2012; Sáez et al., 2013).

Does functional gap junctional communication occur between microglia and other brain cells? According to Dobrenis et al. (2005) microglial cells possess the potential not only to build functional gap junctions through $\mathrm{C} \times 36$ but also to establish this type of communication with hippocampal neurons. These authors observed Cx36 expression in microglia and the presence of electrical coupling between microglia with low unitary conductance $(<20 \mathrm{pS})$ and very low voltage sensitivity, which are properties of Cx36 GJCs but not other connexins (Srinivas et al., 1999; Teubner et al., 2000). These heterocellular interactions mediated by neuro-microglial gap junctions demonstrate anatomical and functional correlations neural progenitor cells (NPCs) isolated from the subventricular zone (SVZ). Talaverón et al. (2014) identified gap junctions between implanted NPCs and host microglia at the ultrastructural level in animals lesioned by axotomy. In a follow-up study, NPCs and microglia established functional gap junctions during coculture as measured by LY dye transfer (Talaverón et al., 2015). Multiple connexins are likely involved in this phenomenon 
because both Cx45 and Cx43 are expressed in NPCs (Talaverón et al., 2015), and both connexins have also been found in microglia (Dobrenis et al., 2005; Higashi et al., 2011). Thus, coupling between microglial cells and NPCs sustains the reciprocal signaling necessary for the proper development of neurogenic niches, including the SVZ (Talaverón et al., 2015). Consistent with this view, microglia and NPCs exhibit close spatial interactions in the SVZ neurogenic niche, and their interplay affects microglial functions and NPC fate (e.g., proliferation, differentiation and survival; Mäkelä et al., 2010; Mosher et al., 2012; Liu et al., 2013; Shigemoto-Mogami et al., 2014). Alternatively, given that the conservation of implanted NPCs depends on the immunomodulatory and neuroprotective molecules released by microglia (Martino and Pluchino, 2006), gap junction coupling among these cell types has the potential to be critical for experimental neural cell therapies that exert beneficial effects on recovery after brain injury.

Recently, two independent groups questioned the existence of functional microglial coupling ex vivo. Employing brain slices derived from CX3CR1-EGFP mice, Wasseff and Scherer (2014) failed to detect the transfer of sulforhodamine-B (SR-B) between injected microglia and any other cell type, including EGFP-positive microglia. Similar observations were also reported for neocortex slices from an Alzheimer's mouse model and mice exposed to a single lipopolysaccharide (LPS) injection (Wasseff and Scherer, 2014). Furthermore, control microglia or microglia found within the glioma environment and stab wound areas were not coupled by gap junctions based on the transfer of biocytin or sulforhodamine101 (SR101; Richter et al., 2014). Considering this controversy in light of early experiments favoring in vitro microglial coupling (Eugenín et al., 2001; Martínez et al., 2002; Garg et al., 2005), one may question whether SR-B, biocytin or SR101 are appropriate dyes to observe coupling among microglia. GJCs formed by different connexins exhibit specific permeability properties depending on the size, shape and charge of the molecules (Harris, 2007). Most studies claiming functional coupling among microglia were performed by microinjecting LY (Eugenín et al., 2001; Martínez et al., 2002; Garg et al., 2005; Shaikh et al., 2012; Sáez et al., 2013). Therefore, the discrepancies surrounding functional coupling likely arise from the different methods employed to assess functional gap junction communication.

Activated microglia are the major antigen presenting cells (APCs) in the CNS (Almolda et al., 2015). APCs take up antigens and process them into proteolytic peptides to generate major histocompatibility complexes (MHCs), which are located on the cell surface and initiate a proper adaptive immune response by activating $\mathrm{CD} 4^{+}$and $\mathrm{CD} 8^{+} \mathrm{T}$ cells (van Kasteren et al., 2014). APC-induced $T$ cell stimulation relies on a mechanism involving the assembly of a specialized supramolecular structure known as the immunological synapse. This structure engages $\mathrm{T}$ cell receptors (TCRs) through MHC-peptide complexes on APCs (Grakoui et al., 1999). In the pioneering work by Neijssen et al. (2005), the transfer of small peptides $(\sim 1.8 \mathrm{kDa})$ between Cx43-transfected cells represents a new mechanism for antigen cross-presentation between APCs and T cells. In this context, dendritic cells (DCs), which are professional APCs, establish functional GJCs among themselves and with $\mathrm{T}$ cells, thereby contributing to antigen transfer and DC activation as well as cross-presentation during $\mathrm{T}$ cell activation at the immunological synapse (Matsue et al., 2006; Corvalán et al., 2007; MendozaNaranjo et al., 2007, 2011; Elgueta et al., 2009). Whether gap junctions are crucial for the hypothetical transfer of antigen peptides among activated microglia or whether these channels cross-present antigens to $\mathrm{T}$ cells remains an open question. Microglia possess the majority of the machinery to crosspresent antigens. Indeed, microglia express MHCs and costimulatory molecules following a wide range of brain injuries, including LPS-induced inflammation, ischemia, axotomy and experimental autoimmune encephalomyelitis (Almolda et al., 2015).

\section{FUNCTIONAL HEMICHANNELS AND PANNEXONS IN MICROGLIA}

To date, the functional expression of HCs in microglia has been documented in different studies (Table 2). Pioneering observations by Takeuchi et al. (2006) noted that Cx32 possesses the ability to form functional HCs in microglia. TNF- $\alpha$ induces microglial glutamate release through the opening of $\mathrm{Cx} 32 \mathrm{HCs}$, a response dramatically suppressed by a mimetic peptide against Cx32 ( ${ }^{32}$ Gap27; Takeuchi et al., 2006; Figure 2). Moreover, glutamate release strongly correlates with the number of $\mathrm{Cx} 32$ HCs available on the microglial cell surface, suggesting a possible role for TNF- $\alpha$ in the sorting and/or trafficking of $\mathrm{Cx} 32$. The TNF- $\alpha$-induced release of glutamate via $\mathrm{Cx} 32$ HCs triggers neuritic beading and neuronal death, as observed by phase contrast microscopy and terminal deoxynucleotidyl transferasedUTP nick end labeling (TUNEL) analysis (Takeuchi et al., 2006). Thus, the opening of glial cell HCs is detrimental for normal neuronal functions. These findings were corroborated by other groups who performed dye uptake experiments in which TNF- $\alpha$ by itself induced HC opening in human microglial CHME-5 cells (Shaikh et al., 2012). Similarly, TNF- $\alpha$ plus IFN- $\gamma$ evoked dye uptake in EOC20 microglial cells via a mechanism sensitive to the pharmacological inhibition of HCs and pannexons (Sáez et al., 2013). These findings, as well as the observation that TNF- $\alpha$ plus IFN- $\gamma$ increases the expression of Cx43 and Panx1, favors a role for Cx43 HCs and Panx1 channels as major targets of inflammatory mediators (Sáez et al., 2013).

Reinforcing the hypothesis that microglial Cx32 HCs are key players in neurotoxicity, glutamate released via these protein conduits was critical for the induction of neuronal damage during brain ischemia (Takeuchi et al., 2008) and experimental autoimmune encephalomyelitis (Shijie et al., 2009) in studies from Suzumura's group. Unfortunately, the involvement of $\mathrm{Cx} 32 \mathrm{HCs}$ in these brain pathologies was deduced based on the positive outcome of disease progression achieved by carbenoxolone (CBX) administration (Takeuchi et al., 2008; Shijie et al., 2009). CBX is a widely used gap junction blocker that also inhibits Panxl channels $(\sim 5 \mu \mathrm{M})$ but does not 
distinguish between Panx1 channels and HCs at concentrations above 50 MM (Bruzzone et al., 2005; D'hondt et al., 2009). Therefore, it is premature to draw conclusions regarding the true participation of microglial Cx32 HCs in the progression of brain disorders in the studies described above. However, a recent study substantiated the involvement of microglial Cx32 HCs in Rett syndrome, which is a neurodevelopmental disorder that affects young girls and is primarily caused by loss-of-function mutations in the X-linked MECP2 encoding methyl-CpG-binding protein 2 (MeCP2; Chahrour and Zoghbi, 2007). In this study, MeCP2null microglia released large amounts of glutamate due to increased production by glutaminase and increased release through Cx32 HCs (Maezawa and Jin, 2010). Strikingly, the Cx32 HC blockers ${ }^{32}$ Gap27 and ${ }^{32}$ Gap24 dramatically prevented microglia-mediated dendritic atrophy and the reduction of dendritic (MAP2 and Ac-TN) and postsynaptic protein density (PSD95 and GRIP1) and the glutamate receptor subunits NR1, GluR2/3, and GluR6/7 (Maezawa and Jin, 2010). Thus, Cx32 HCs represent potential pharmacological targets for therapies to counter the harmful effects linked to microglial dysfunction and miscommunication with neurons during Rett syndrome.

Microglia under a resting surveillance state express significant levels of Panx1 (Higashi et al., 2011; Orellana et al., 2011b, 2014; Rigato et al., 2012; Sáez et al., 2013) but not Panx2 (Rigato et al., 2012). Similar to the observations with connexins, Panx1 is upregulated in microglia stimulated with different proinflammatory agents, including IFN- $\gamma$ (Shestopalov and Slepak, 2014), amyloid- $\beta$ peptide (A $\beta$; Orellana et al., 2011b), TNF- $\alpha$ plus ATP (Sáez et al., 2013), TNF- $\alpha /$ IFN- $\gamma$ (Sáez et al., 2013) and TNF- $\alpha /$ IL-1 $\beta$ (Sáez et al., 2013). The functional expression of pannexons in microglia is a relatively new discovery stemming from studies in which $A \beta$ induces dye uptake and macroscopic currents in these cells (Orellana et al., 2011b). These responses are inhibited by mimetic peptides and pharmacological blockers against Panx1 channels ( ${ }^{10}$ panx $1, \mathrm{E} 1 \mathrm{~b}$ and probenecid) or $\mathrm{Cx} 43$ HCs (Gap26, Gap27 and $\mathrm{Cx} 43^{\mathrm{E} 2}$ ), whereas microglial cultures from $\mathrm{Cx} 43$-null mice are unaffected by $\mathrm{A} \beta$ treatment (Orellana et al., 2011b). The currents recorded at negative holding potentials $(-60 \mathrm{mV})$ reveal unitary events with conductances near $\sim 500$ and $\sim 220 \mathrm{pS}$; these conductances do not differ greatly from those observed for Panx1 channels and Cx43 HCs (Contreras et al., 2003; Bao et al., 2004). Additionally, channel opening correlates with microglial activation, increased surface levels of Panx1 and Cx43, and the prominent release of glutamate and ATP via a pathway sensitive to Panx1 channel and Cx43 HC blockers (Orellana et al., 2011b). Notably, N-methyl-Daspartate $(\mathrm{NMDA})$ and $\mathrm{P}_{2} \mathrm{X}_{7}$ receptor activation triggered by these gliotransmitters results in the opening of Panxl channels in neurons, resulting in detrimental consequences for neuronal survival (Orellana et al., 2011b).

The question of whether microglial pannexons and/or HCs indeed participate in the onset and progression of Alzheimer's disease $(\mathrm{AD})$ remains unanswered. A recent study by Takeuchi et al. (2011) described a possible role for microglial Cx32 HCs as major regulators of the brain damage observed in AD. The BBB-permeable Cx32 HC blocker INI-0602 not only ameliorated symptoms in two amyotrophic lateral sclerosis (ALS) mouse models, but also improved memory deficits in the APP/PS1 transgenic model of AD (Takeuchi et al., 2011). Interestingly, INI-0602 successfully inhibited microglial glutamate release in vivo, potentially implicating microglial $\mathrm{HC}$ dependent excitotoxicity in disease progression in ALS and AD mouse models. Although INI-0602 reduces Cx32 HCmediated glutamate release in cultured microglia (Takeuchi et al., 2011), it will be interesting to examine whether this HC blocker maintains its specificity over other channels in vivo. The functional detection of microglial HCs and/or pannexons in brain slices derived from $\mathrm{AD}$ mouse models using pharmacological (e.g., mimetic peptides) and molecular (e.g., protein downregulation) approaches will fully elucidate the involvement of these microglial channels in $\mathrm{AD}$.

Recently, the opening of microglial pannexons was described in mouse models of stress-related mental disorders, such as anxiety and major depression. In dye uptake experiments, acute and chronic restraint stress protocols activated microglial Panx1 channels in hippocampal slices, with chronic restraint stress exerting the strongest effects on these channels (Orellana et al., 2015). This response did not occur in hippocampal slices from Panx1 null mice and was fully suppressed by NMDA and $\mathrm{P}_{2} \mathrm{X}_{7}$ receptor blocking (Orellana et al., 2015). Restraint stress also elicits the opening of astroglial and neuronal HCs and the concomitant involvement of the $\mathrm{Cx} 43$ and Panx1 channelforming proteins in these responses, respectively (Orellana et al., 2015). Interestingly, glutamate and ATP release is highly promoted in hippocampal slices derived from mice subjected to restraint stress, but this phenomenon is entirely blunted after treatment with Panx1 channel, Cx43 HC and NMDA and $\mathrm{P}_{2} \mathrm{X}_{7}$ receptor inhibitors (Orellana et al., 2015). The authors proposed that chronic restraint stress might increase brain levels of glucocorticoids (GCs), resulting in further activation of the $\mathrm{NMDA} / \mathrm{P} 2 \mathrm{X}_{7}$ receptors in microglia and astrocytes. Consistent with this idea, chronic stress triggers NMDA and GG receptor-mediated microglial activation (Nair and Bonneau, 2006), whereas GC exposure primes cytokine release from microglia ex vivo (Frank et al., 2007); the latter effect is a wellknown inducer of ATP and glutamate release through glial cell HCs (Takeuchi et al., 2006; Avendaño et al., 2015). In summary, $\mathrm{HC}$ opening alters brain concentrations of different transmitters and thus represents an overlooked form of miscommunication that modifies the proper function of neuronal circuits in people suffering from stress-related mental disorders.

\section{CROSSTALK BETWEEN ASTROCYTES AND MICROGLIA REGULATES CONNEXIN AND PANNEXIN-BASED CHANNELS}

Microglia and astrocytes respond to brain injury with distinctive spatial and temporal activation patterns and their crosstalk appears to be critical for neuronal outcomes (Liu et al., 2011). The release of gliotransmitters, cytokines and growth factors represents the primary mechanism by which glial cells communicate with one another and respond to neural activity 
(Färber and Kettenmann, 2006; Koizumi, 2010). Activated microglia modulate connexin expression and functional GJC and HC activity in astrocytes (Rouach et al., 2002; Faustmann et al., 2003; Hinkerohe et al., 2005; Même et al., 2006; Retamal et al., 2007a; Orellana et al., 2011a). Normally, astrocytes are strongly coupled through gap junctions and express high levels of Cx43 (Giaume et al., 1991). However, when they are cultured with resting microglia, $\mathrm{Cx} 43$ levels and dye coupling are obviously reduced (Rouach et al., 2002) and potentiated by LPS (Même et al., 2006). Interestingly, the above response is mimicked with conditioned media (CM) harvested from microglia pretreated with LPS, implying soluble factors released by microglia modulate astrocytes (Même et al., 2006). Indeed, studies involving Enzyme-Linked ImmunoSorbent Assay (ELISA), immunoneutralization and cytokine receptor blocking reported that IL- $1 \beta$ and TNF- $\alpha$ are soluble factors affecting $\mathrm{Cx} 43$ expression and GJC functions in astrocytes (Même et al., 2006). Importantly, the influence of microglia on the function of astroglial connexins extends beyond gap junctions and also impacts the opening of HCs. Astrocytes exposed to CM from LPS-stimulated microglia or IL- $1 \beta$ plus TNF- $\alpha$ exhibit a conspicuous increase in $\mathrm{HC}$ activity as determined from unitary current conductance measurements and dye uptake experiments (Retamal et al., 2007a). This effect occurs in parallel with the inhibition of dye coupling; thus, both cytokines released by microglia regulate gap junctions and HCs in an opposing manner in astrocytes (Retamal et al., 2007a). Notably, p38 MAPK pathway inhibition completely reduces the dual influence of microglia in astroglial connexin channels (Retamal et al., 2007a). Supporting these findings, WIN and methanandamide, which are two well-known cannabinoids that counteract p38 MAPK signaling (Carracedo et al., 2004), impede the LPSmediated release of IL- $1 \beta$ and TNF- $\alpha$ from microglia, thereby limiting their control of astroglial connexins (Froger et al., 2009).

Recently, factors released by astrocytes were shown to counteract the immunomodulatory actions of LPS in microglia, including ATP release (Orellana et al., 2013b). In a recent study, LPS-stimulated microglia produced large amounts of nitric oxide (NO), which was accompanied by a significant increase in $\left[\mathrm{Ca}^{2+}\right]_{i}$ and ATP release (Orellana et al., 2013b; Figure 3). These responses were effectively blocked by L-N6, NS-398, SC-560 and SC 19220, which are selective inhibitors of iNOS, cyclooxygenase-1 $\left(\mathrm{COX}_{1}\right)$, cyclooxygenase-2 $\left(\mathrm{COX}_{2}\right)$ and the $\mathrm{PGE}_{2}$ receptor $\mathrm{EP}_{1}$, respectively (Orellana et al., 2013b). Interestingly, LPS-induced ATP release was not detected after blocking Panx1 channels with probenecid and ${ }^{10}$ panx1 or in microglia treated with siRNA targeting Panxl (Orellana et al., 2013b). This peculiar pharmacology suggested a direct link between LPS and Panxl channel opening, which occurred in response to $\mathrm{NO}$ production, $\mathrm{COX}$ activation and $\mathrm{PGE}_{2}$ release. Remarkably, Transforming growth factor beta 1 (TGF$\beta 1)$ release by activated astrocytes completely abolished the LPS-induced increase in NO production, $\left[\mathrm{Ca}^{2+}\right]_{i}$, ATP release and Panx1-dependent dye uptake (Orellana et al., 2013b; Figure 3). Moreover, the Panx1-dependent release of ATP and subsequent activation of the $\mathrm{P}_{2} \mathrm{Y}_{1}$ and $\mathrm{P} 2 \mathrm{X}_{7}$ receptors were crucial for the preservation of LPS-mediated NO production in microglia (Orellana et al., 2013b). Subsequent experiments corroborated the connection between iNOS/COXs/EP 1 receptor signaling and the functional opening of Panxl channels in microglia. Prenatal nicotine exposure and a postnatal highfat/cholesterol diet after weaning increase the opening of astroglial Cx43 HCs and Panx1 channels in microglia and neurons (Orellana et al., 2014). The opening of microglial pannexons is not paralleled by significant changes in Panx1 expression but is associated with the release of ATP via a mechanism dependent on the activation of the iNOS/COX $2 / \mathrm{EP}_{1}$ receptor pathway and signaling via $\mathrm{P}_{2} \mathrm{X}_{7}$ receptors (Orellana et al., 2014).

How does the ATP released through microglial Panx1 channels contribute to cell-to-cell communication in the brain parenchyma? ATP is a crucial transmitter involved in the crosstalk between brain cells (Fields and Burnstock, 2006) and has often been linked with the activation and chemotaxis-related features of microglia (Honda et al., 2001). In the CNS, one of the major signs driving microglia into an "activated" state is a prominent rise in extracellular ATP levels, potentially in response to tissue injury. Given this background, microglial sensitivity to ATP relies on the expression of the two purinergic receptor families: G-protein coupled-type P2 receptors (P2Y receptors, $\mathrm{P} 2 \mathrm{YRs}$ ) and ionotropic $\mathrm{P} 2$ receptors (P2X receptors, P2XRs; Inoue, 2002). Upon their activation, P2YRs/P2XRs induce membrane ruffling and ramification of cultured microglia (Nolte et al., 1996) as well as the release of different messengers and signaling molecules, such as TNF- $\alpha$ and IL-1 $\beta$ (Inoue, 2002). The majority of these paracrine mediators reinforce microglial activation (Chao et al., 1995; Kuno et al., 2005) and lead to the opening of microglial pannexons and HCs (Takeuchi et al., 2006; Shaikh et al., 2012; Sáez et al., 2013). In leading-edge studies by Davalos et al. (2005), extracellular ATP controlled microglial chemotactic responses in the brain parenchyma; moreover, its release from injured tissue (particularly astrocytes) mediated a rapid microglial reaction towards the damage site. Because CBX and flufenamic acid (nonspecific blockers of HCs and pannexons) strongly inhibit microglial responses towards a site of injury, both channels were suggested to be major astroglial conduits for ATP release during rapid microglial responses to local brain trauma (Davalos et al., 2005). Although a great deal remains to be learned about the events affecting the opening of $\mathrm{HCs}$ and/or pannexons in microglia during brain trauma, this study demonstrated a role for connexins and pannexins in microglial branch dynamics.

Astrocytes are the primary partnering cells that share ATPmediated communication with microglia. Astrocytes release ATP through Cx43 HCs and/or Panx1 channels (Cotrina et al., 1998; Braet et al., 2003; Iglesias et al., 2009; Garré et al., 2010; Orellana et al., 2011a,b; Suadicani et al., 2012), resulting in the activation of P2XRs/P2YRs and the regenerative release of ATP via these channels (Iglesias et al., 2009; Garré et al., 2010; Suadicani et al., 2012). This mechanism of ATP-induced ATP release is critical for the spread of $\mathrm{Ca}^{2+}$ waves (Guthrie et al., 1999; Anderson et al., 2004) and constitutes a critical pathway through which astrocytes 


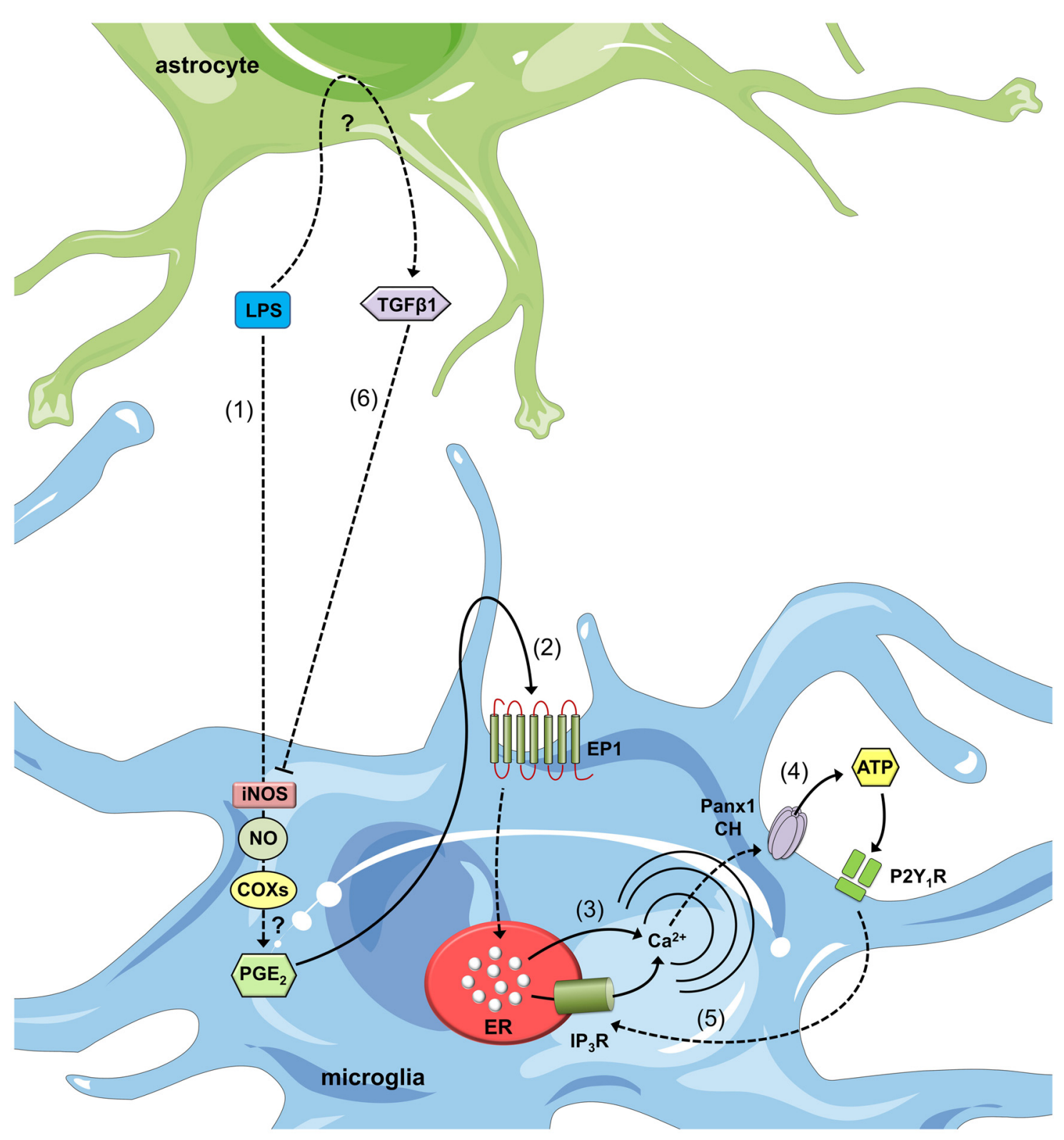

FIGURE 3 | Astroglial modulation of ATP-induced $\mathrm{Ca}^{2+}$ dynamics in LPS-stimulated microglia. After LPS stimulation, microglia respond with intracellular signal transduction, leading to iNOS activation, nitric oxide (NO) production, cyclooxygenase (COX) activation and prostaglandin E2 (PGE $)$ production via unknown mechanisms (1). $\mathrm{PGE}_{2}$ released by microglia binds to the EP1 metabotropic receptor (2) to induce $\mathrm{Ca}^{2+}$ release from intracellular stores (3). This release increases $\left[\mathrm{Ca}^{2+}\right]_{\text {, }}$, which is known to open Panx1 channels $(\mathrm{CHs})$ and subsequently release ATP (4). ATP released via Panx1 $\mathrm{CHs}$ and its degradation to ADP activate P2Y 1 receptors, which induce $\mathrm{IP}_{3}$ receptor activation and the further release of $\mathrm{Ca}^{2+}$ stored in the endoplasmic reticulum (5). Astrocytes stimulated with LPS release transforming growth factor $\beta 1$ (TGF $\beta 1$ ) (6), which inhibits LPS-induced intracellular signal transduction and causes iNOS activation. An alternative negative feedback loop mediates the inhibitory effects of ATP on Panx1 channels (not depicted). Finally, paracrine release of ATP from microglia acts upon neighboring or distant microglia, resulting in an additional feed-forward mechanism (not depicted).

exert their immunomodulatory actions over microglia (Verderio and Matteoli, 2001; Schipke et al., 2002). Indeed, purinergic receptors and the activation of $\mathrm{HCs}$ and pannexons represent an essential mechanism for the maintenance of the regenerative release of ATP in microglia because acute application of this gliotransmitter induces the opening of $\mathrm{Cx} 43 \mathrm{HCs}$ and Panx1 channels in these cells (Bernier et al., 2012; Sáez et al., 2013).
How does ATP activate P2XRs in microglia? Extracellular ATP produces different outcomes in terms of the P2XR-mediated activation of macrophages and microglia depending on the treatment period and concentration used (Baroja-Mazo et al., 2013). For $P 2 X_{7}$ Rs, brief treatment with ATP stimulates small cationic currents of 10-30 pS, whereas repetitive or longlasting application of ATP generates large currents of $\sim 440 \mathrm{pS}$ 
and the rapid uptake of large molecules (up to $900 \mathrm{kDa}$ ). Potentially, $\mathrm{P} 2 \mathrm{X}_{7} \mathrm{R}$ conductance increases over time, resulting in the formation of a large pore to facilitate the passage of molecules; alternatively, $\mathrm{P} 2 \mathrm{X}_{7} \mathrm{Rs}$ activates a second non-selective permeability pathway (Baroja-Mazo et al., 2013). Panx1 channels mediate $\mathrm{P} 2 \mathrm{X}_{7} \mathrm{R}$-dependent permeability for large molecules in macrophages (Pelegrin and Surprenant, 2006) and microglia (Bernier et al., 2012) but do not participate in microglial $\mathrm{P} 2 \mathrm{X}_{4} \mathrm{R}$ pore formation (Bernier et al., 2012). Coincident findings related to the latter observation were recently described in mouse peritoneal macrophages (Seil et al., 2010), and a Panx1independent model has been proposed for $\mathrm{P} 2 \mathrm{X}_{2} \mathrm{R}$ large molecule permeability (Chaumont and Khakh, 2008). Future studies will elucidate the participation of Panxl channels in the longlasting activation of other P2XRs in addition to $\mathrm{P} 2 \mathrm{X}_{7} \mathrm{Rs}$ in microglia.

$\mathrm{P}_{2} \mathrm{X}_{7} \mathrm{R}$ activation drives the release of ATP in microglia via at least one mechanism involving HCs and/or pannexons. Although $\mathrm{P} 2 \mathrm{X}_{7} \mathrm{R}$ activation increases $\left[\mathrm{Ca}^{2+}\right]_{\mathrm{i}}$ (Baroja-Mazo et al., 2013) and opens Cx43 HCs and Panx1 channels (Locovei et al., 2006b; De Vuyst et al., 2009; De Bock et al., 2012; Wang et al., 2012), the Panx1-dependent release of ATP relies on protein-protein interactions between $\mathrm{P}_{2} \mathrm{X}_{7} \mathrm{Rs}$ and Panx1 (Locovei et al., 2007). Supporting this idea, Panx1 coimmunoprecipitates with $\mathrm{P}_{2} \mathrm{X}_{7} \mathrm{Rs}$ (Pelegrin and Surprenant, 2006; Silverman et al., 2009; Li et al., 2011; Poornima et al., 2012; Hung et al., 2013), and proline 451 in the C-terminal tails of these receptors has been implicated in this interaction (Iglesias et al., 2008; Sorge et al., 2012). P2YRs activation constitutes a second mechanism by which ATP is released from microglia. Because P2YRs mediate $\mathrm{Ca}^{2+}$ release from intracellular stores, they induce $\mathrm{HC} /$ pannexon opening linked to the consequential release of ATP from microglia, which was previously demonstrated for other cell types (Locovei et al., 2006a; Orellana et al., 2012a; Zhang et al., 2012). Although some observations support exocytosis as the predominant route for ATP release in microglia (Imura et al., 2013), Panx1 channels and $\mathrm{Cx} 43 \mathrm{HCs}$ facilitate its release after stimulation with LPS (Orellana et al., 2013b), $\mathrm{A} \beta$ (Orellana et al., 2013b) or $\mathrm{ZnCl}_{2}$ (Higashi et al., 2011).

Interestingly, $\mathrm{P} 2 \mathrm{X}_{7} \mathrm{R}$-dependent opening of Panx 1 channels has been linked to the secretion of IL-1 $\beta$ by a mechanism involving the activation of the inflammasome (Pelegrin and Surprenant, 2006, 2007, 2009; Kanneganti et al., 2007). During an infection, innate immune cells recognize different pathogenassociated molecular patterns (PAMPs) and damage-associated molecular patterns (DAMPs) expressed and released by invading pathogens and dying cells, respectively (Bianchi, 2007). Members of the NOD-like receptor (NLR) family recognize PAMPs and DAMPs and in association with the adaptor apoptosis speck-like protein containing a CARD (ASC) constitute the inflammasome platform (Martinon et al., 2002), which is critical for caspase1 activation, production of the IL- $1 \beta$ and proper host defense response (Netea et al., 2010). ATP is a well-known DAMP released from damaged or dying cells after trauma that promotes inflammasome activation by acting at $\mathrm{P} 2 \mathrm{X}_{7} \mathrm{R}$ (Ayna et al., 2012). Protein-to-protein interaction between $P 2 X_{7} R$ and $P a n x 1$, as well as increase in extracellular $\mathrm{K}^{+}$stimulate Panxl channel opening, thus releasing more ATP into the extracellular space (Pelegrin and Surprenant, 2006, 2007, 2009; Kanneganti et al., 2007). In neurons and astrocytes, opening of Panx1 channels leads to caspase- 1 activation by a mechanism involving the association of Panx1 with components of the multiprotein inflammasome complex, including the $\mathrm{P} 2 \mathrm{X}_{7} \mathrm{R}$ (Silverman et al., 2009; Murphy et al., 2012; Minkiewicz et al., 2013). Although IL-1 $\beta$ secretion in microglia depends on activation of the inflammasome (Terada et al., 2010; Burm et al., 2015), whether Panx1 channels participate in this process remain to be elucidated.

In seminal studies by Bruzzone et al. (2001), Cx43 HCs promoted cyclic ADP-ribose (cADPR) signaling by inducing the release of $\mathrm{NAD}^{+}$. After cyclization of $\mathrm{NAD}^{+}$by $\mathrm{CD} 38$, this ectoenzyme produces cADPR, which is a potent endogenous agonist of ryanodine receptors (RyRs) that serves as a universal mobilizer of $\mathrm{Ca}^{2+}$ from intracellular stores (Malavasi et al., 2008). Moreover, HCs not only mediate the outward passage of $\mathrm{NAD}^{+}$but also import cADPR into macrophages to activate intracellular $\mathrm{Ca}^{2+}$ mobilization (Song et al., 2011). Interestingly, CD38 plays a key role in the basal survival of microglia due to its inhibitory effects on $\mathrm{Cx} 43$ HC-dependent ATP release (Ma et al., 2014). Downregulation of CD38 or pharmacological inhibition of RyRs increases ATP release, microglial activation and death via a mechanism involving the opening of $\mathrm{Cx} 43$ HCs. Molecular (siRNA) and pharmacological inhibition of Cx43 HCs dramatically ameliorates the decreased CD38/cADPR signaling-induced release of ATP, NO production and apoptosis by microglia (Ma et al., 2014). Cx43 HC opening and ATP release are likely caused by the production of superoxide because treatment with the broadly used antioxidant NAC strongly attenuates RyR inhibition-mediated dye uptake in microglia (Ma et al., 2014). Accordingly, oxidative stress opens Cx43 HCs in astrocytes (Retamal et al., 2006) and HeLa Cx43 transfectants (Retamal et al., 2007b). The Cx43 HC-dependent release of ATP activates $\mathrm{P} 2 \mathrm{X}_{7} \mathrm{R}$, resulting in a mechanism of ATP-induced ATP release that leads to microglial activation and cell death. Although ATP-mediated HC opening has been linked to cell death in neurons and astrocytes (Orellana et al., 2011a,b; Rovegno et al., 2015), additional studies are required to fully elucidate whether similar mechanisms result in microglial cell death.

Together, this evidence supports the hypothesis that regenerative Panx1/Cx43-dependent ATP release from astrocytes and microglia relies on purinergic, CD38/cADPR and $\mathrm{Ca}^{2+}$ signaling, resulting in further stimulation of neighboring microglia (Fontainhas et al., 2011; Orellana et al., 2013b; Ma et al., 2014). Thus, P2YR/P2XR activation is turned off in part by ATP diffusion to distal regions as well as the desensitization of these receptors and the degradation of extracellular ATP by exonucleases (Fields and Burnstock, 2006). Similarly, ATP directly inhibits Panx1 channels (Qiu and Dahl, 2009), thereby constituting an alternative negative feedback loop in the glial network. Another regulatory mechanism relies on the inhibitory effects of the increase in $\left[\mathrm{Ca}^{2+}\right]_{\mathrm{i}}$ over $\mathrm{Cx} 43$ HCs due to purinergic signaling activation. Accordingly, 
Cx43 HCs exhibit a biphasic and bell-shaped dependency on $\left[\mathrm{Ca}^{2+}\right]_{\text {i }}$ (i.e., concentrations below $500 \mathrm{nM}$ result in their activation, whereas concentrations over $500 \mathrm{nM}$ trigger a negative feedback loop; De Vuyst et al., 2009; De Bock et al., 2012; Wang et al., 2012). In the inflamed CNS, astrocytes potentially suppress this self-perpetuating mechanism of ATP release in microglia by secreting anti-inflammatory factors such as TGF- $\beta$, as previously observed (Orellana et al., 2013b).

\section{PANNEXONS REGULATE MICROGLIAL MIGRATION AND MORPHOLOGY}

Based on a large body of evidence, neurons are an important source of molecules that dictate the morphology, dynamic behavior and chemotaxis of microglia (Ey et al., 2009; Domercq et al., 2013). In particular, pannexons play a crucial role in this crosstalk. According to Fontainhas et al. (2011), the Panx1-dependent release of ATP in response to glutamatergic neurotransmission increased dendritic morphology and process dynamics in microglia in retinal explants. Notably, ATP-induced microglial changes were observed even upon glutamatergic blockade, whereas purinergic receptor inhibition decreased this response despite glutamatergic stimulation, suggesting ATP release occurs "downstream" of glutamate receptor activation (Fontainhas et al., 2011). Although the identity of the cells responsible for ATP release in the retina has not been reported, possible candidates include astrocytes, Müller cells, neurons and microglia themselves.

A recent study that performed in vivo time-lapse imaging of both microglial morphology and neuronal activity in the optic tectum of larval zebrafish revealed the crucial role of Panx1 channels on tectal neurons in the dynamic orientation of resting microglial processes ( $\mathrm{Li}$ et al., 2013). Membrane depolarization evoked large probenecid-sensitive outward currents in tectal neurons but not in microglia. Moreover, blockade of Panx1 channels with probenecid or CBX significantly reduced the number of bulbous endings (microglial processes that dynamically contact the neuronal soma; Li et al., 2013). Acute treatment with the ATP-hydrolyzing enzyme apyrase or the purinergic receptor blocker suramin strongly reduced the percentage of bulbous endings, suggesting the involvement of extracellular ATP and/or ADP in regulating the baseline motility of resting microglial processes (Li et al., 2013). ATP and purinergic signaling have been linked to microglial migration towards distant lesions in leeches (Samuels et al., 2010, 2013). In the leech, a single giant glial cell with structural and functional features similar to mammalian astrocytes and oligodendrocytes ensheathes axon tracts that connect neuronal cell bodies (Deitmer et al., 1999). Apyrase and CBX inhibit the ATP-dependent migration of microglia and their aggregation at lesions (Samuels et al., 2013). The specific downregulation of innexons (i.e., the pannexon homologs in non-chordates) in the giant glia dramatically reduce dye efflux and microglial migration, suggesting the requirement for innexon-dependent release of ATP from glia for microglial chemotaxis at sites of injury (Samuels et al., 2013). Although the question of whether astroglial or neuronal pannexons exert differential influences over microglial migration depending on the context of injury remains open, purinergic signaling is clearly part of this process.

\section{CONCLUSIONS AND FUTURE DIRECTIONS}

The functional state of HCs, pannexons and GJCs is finely regulated during inflammation in microglial cells. In this context, different PAMPs (e.g., AGEs, LPS) and DAMPs (e.g., ATP) are recognized by microglial pattern recognition receptors (PRRs), resulting in activation of the NF- $\kappa \beta$ pathway and the inflammasome complex. These pathways induce the autocrine/paracrine release of pro-inflammatory cytokines (e.g., IL- $1 \beta$ and TNF- $\alpha$ ), which activate the opening of connexin- and pannexin-based channels and the release of ATP through Cx43 HCs and Panx1 channels.

Microglial activation is a highly dynamic and complex process whose development is supported by the transfer of messengers through GJCs and paracrine signaling via the functional opening of HCs and pannexons. The passage of molecules and ions likely relies on the activation of different intracellular pathways based on the degree and stage of microglial activation. Therefore, gap junction communication reflects the ability of an activated microglial cell to recruit resting microglia or to establish direct communication with other cells in the CNS to favor cross-presentation at the immune synapse or promote the repair of damaged tissue (Figure 4). Alternatively, $\mathrm{HC} /$ pannexon opening sustains the microglial chemotactic responses and dynamics necessary to ensure proper microglial migration to injury sites. Although the impact of the increased microglial GJC activity on neuronal survival is unknown, the opening of microglial HCs and pannexons certainly lead to neuronal damage (Figure 4). Most studies suggest that the release of gliotransmitters (e.g., ATP, glutamate) through $\mathrm{Cx} 43 / \mathrm{Cx} 32 \mathrm{HCs}$ and Panx1 channels is critical to induce neuronal death by a mechanism involving the activation of NMDARs/P2 $\mathrm{X}_{7}$ Rs and Panx1 channels in neurons. Thus, the prevention of HC- and pannexon-mediated microglial activation represents an unexplored strategy to prevent neuronal damage and death during neuroinflammation. Future studies will elucidate the impact of this signaling pathway in neurodegenerative diseases in vivo. The findings discussed here strengthen the emerging concept that the unregulated membrane permeability of HCs, pannexons and GJCs contributes to microglial dysfunction. Thus, connexins as well as pannexins represent potential and alternative targets for therapeutic intervention in neuroinflammatory diseases.

\section{CLINICAL RELEVANCE}

Although the clinical impact of dysfunctional HCs and pannexons in microglia is still unknown, gene mutations and changes in expression or distribution of connexins and pannexins have been implicated in the genesis and progression of different diseases (Penuela et al., 2014; Retamal et al., 2015; Bai, 2016). For instance, germline mutations in genes 


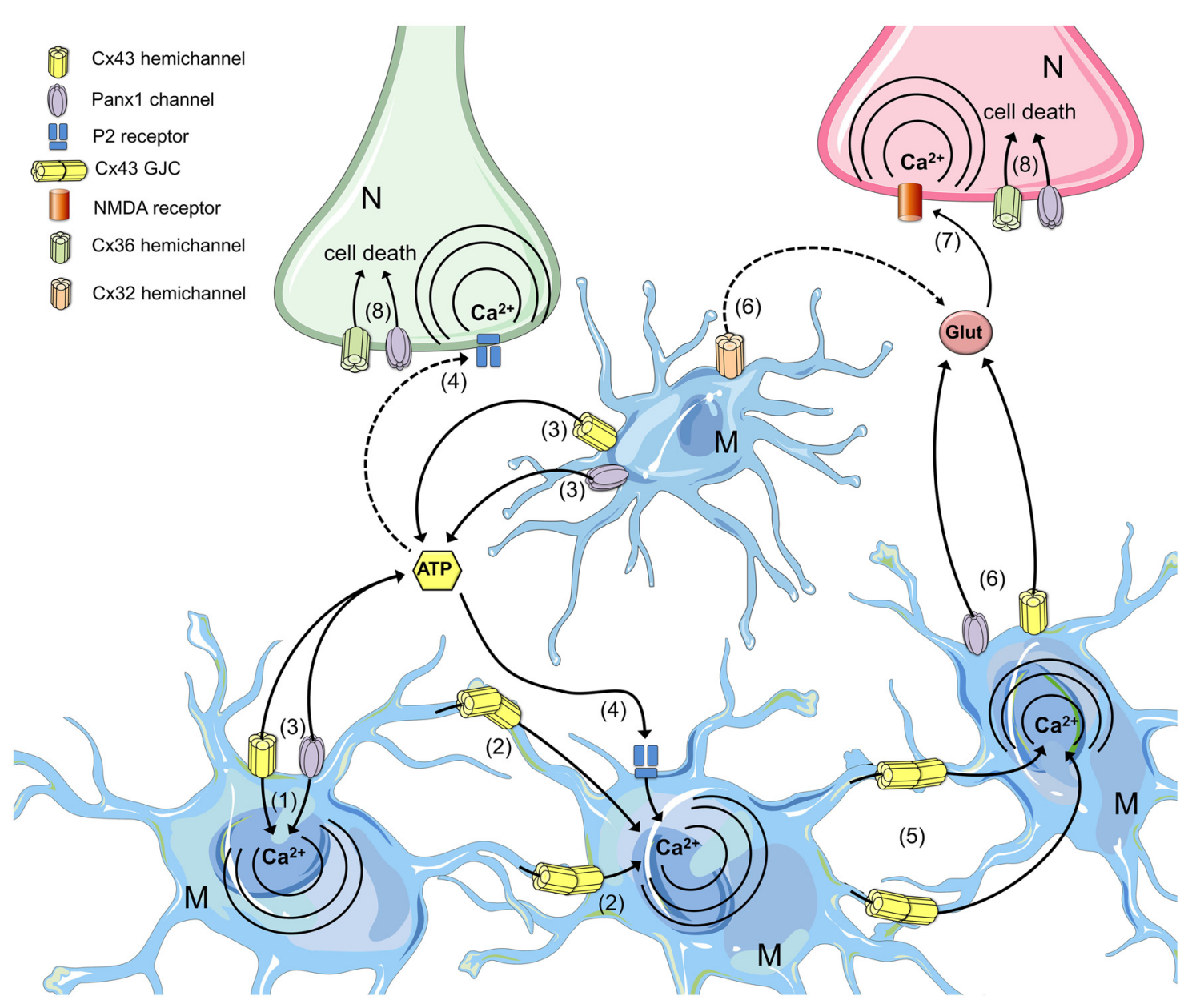

FIGURE 4 | The roles of microglial connexin- and pannexin-based channels in neurodegeneration. Under progressive inflammatory conditions, cytokine production and redox imbalance increase the opening of HCs and pannexons in microglia, permitting the influx of $\mathrm{Ca}^{2+}(1)$ and its spread to neighboring cells through GJCs (2). Hemichannel and pannexon opening in microglia favor the release of ATP (3), which diffuses through the extracellular space to activate membrane purinergic (P2) receptors (4). Intercellular $\mathrm{Ca}^{2+}$ waves propagated via GJCs increase the $\left[\mathrm{Ca}^{2+}\right]_{\mathrm{i}}$ in distant microglia (5), facilitating the release of glutamate through microglial $\mathrm{HCs}$ /pannexons (6) and the further activation of neuronal n-methyl-d-aspartate (NMDA) receptors (7). P2 and NMDA receptor activation in neurons increase the activity of neuronal Panx1 channels and Cx36 HCs, impairing the electrochemical and $\mathrm{Ca}^{2+}$ imbalance that results in cell death (8).

encoding Cx26, Cx30, Cx31, Cx32 and Cx43 are linked with almost the half of all cases of inherited neurosensory deafness (Martínez et al., 2009), whereas Cx32 and Cx47 mutations are associated with X-linked Charcot-Marie-Tooth (Kleopa et al., 2006) and Pelizaeus-Merzbacher-like (Bugiani et al., 2006) diseases, respectively. In addition, mutations in $\mathrm{Cx} 46$ and $\mathrm{Cx} 50$ are connected with congenital cataracts (Gong et al., 2007), whereas people with Cx43 mutations show the developmental disorder oculodentodigital dysplasia (ODDD) that in a few cases is accompanied by palmoplantar keratoderma (Paznekas et al., 2009). Along with the diseases associated with connexin gene mutations, there is another group of pathologies that involve changes in the expression, assembly state or localization of connexins and/or pannexins. The loss of gap junctional communication in different human cell-derived tumors arises as the most remarkable example of connexin regulation during pathology (Jiang and Penuela,
2016). Another illustrative example is the relocalization of $\mathrm{Cx} 43$ and gap junction modulation that participate in arrhythmias and heart failure (Severs et al., 2008). In the CNS, patients with temporal lobe epilepsy exhibit high levels of Panx1 compared to normal people (Jiang et al., 2013), whereas $\mathrm{Cx} 43$, Cx30, Cx36 behave similarly in rodent models of epilepsy (Mylvaganam et al., 2014). In the same context, cortical spreading depression associated to Cx36 and Panx1 dysfunction has been linked to the pathophysiology of migraine with aura (Sarrouilhe et al., 2014). Recently, Cepeda et al. (2015) showed that brain samples from children undergoing Rasmussen encephalitis exhibit an increased expression of Panx1 and Cx36 in Iba-1-positive cells compared to control conditions. These findings put to the forefront the potential therapeutic role that could have connexin and pannexin-derived channels in different neurological disorders. 
One of the most interesting challenges in the connexin and pannexin field is to develop molecular strategies to specifically target the expression and/or function of GJCs, HCs and pannexons. Currently, most pharmacological (e.g., drugs and mimetic peptides) and molecular (e.g., siRNAS and KO mice) tools in animals models do not allow the discrimination between GJC vs. HC/pannexon function (Sáez and Leybaert, 2014). However, recent clinical evidence suggests that these channels could be highly exploitable for pharmacological intervention or serve for genetic screening purposes. At clinical level, two major interesting approaches have been used to modulate connexin/pannexin expression or the channels themselves: targeting transcription/translation (e.g., antisense approaches) and peptidomimetic strategies (e.g., Gap26, Gap27, Peptide5, Gap19 and ACT-1). In this context, nowadays there are four wellknown companies with human therapeutic focus on connexins and pannexins: CoDa Therapeutics Inc. (USA and New Zeland), FirstString Research (USA), Theranexus (France) and Zealand Pharma (Denmark). A general patent search for "connexin" or "pannexin" at the US Patent and Trade-mark Office website reveals more than 500 and 25 issued, respectively. Different drugs and peptides designed to modulate GJC and/or HCs have shown

\section{REFERENCES}

Abascal, F., and Zardoya, R. (2012). Evolutionary analyses of gap junction protein families. Biochim. Biophys. Acta 1828, 4-14. doi: 10.1016/j.bbamem.2012. 02.007

Akira, S., Takeda, K., and Kaisho, T. (2001). Toll-like receptors: critical proteins linking innate and acquired immunity. Nat. Immunol. 2, 675-680. doi: 10. 1038/90609

Almolda, B., González, B., and Castellano, B. (2015). Are microglial cells the regulators of lymphocyte responses in the CNS? Front. Cell. Neurosci. 9:440. doi: 10.3389/fncel.2015.00440

Ambrosi, C., Gassmann, O., Pranskevich, J. N., Boassa, D., Smock, A., Wang, J., et al. (2010). Pannexin1 and Pannexin2 channels show quaternary similarities to connexons and different oligomerization numbers from each other. J. Biol. Chem. 285, 24420-24431. doi: 10.1074/jbc.m110.115444

Anderson, C. M., Bergher, J. P., and Swanson, R. A. (2004). ATP-induced ATP release from astrocytes. J. Neurochem. 88, 246-256. doi: 10.1111/j.1471-4159. 2004.02204.x

Anselmi, F., Hernandez, V. H., Crispino, G., Seydel, A., Ortolano, S., Roper, S. D., et al. (2008). ATP release through connexin hemichannels and gap junction transfer of second messengers propagate $\mathrm{Ca}^{2+}$ signals across the inner ear. Proc. Natl. Acad. Sci. U S A 105, 18770-18775. doi: 10.1073/pnas.08007 93105

Ardiles, A. O., Flores-Muñoz, C., Toro-Ayala, G., Cárdenas, A. M., Palacios, A. G., Muñoz, P., et al. (2014). Pannexin 1 regulates bidirectional hippocampal synaptic plasticity in adult mice. Front. Cell. Neurosci. 8:326. doi: 10.3389/fncel. 2014.00326

Avendaño, B. C., Montero, T. D., Chávez, C. E., von Bernhardi, R., and Orellana, J. A. (2015). Prenatal exposure to inflammatory conditions increases Cx43 and Panx1 unopposed channel opening and activation of astrocytes in the offspring effect on neuronal survival. Glia 63, 2058-2072. doi: 10.1002/glia. 22877

Ayna, G., Krysko, D. V., Kaczmarek, A., Petrovski, G., Vandenabeele, P., and Fésüs, L. (2012). ATP release from dying autophagic cells and their phagocytosis are crucial for inflammasome activation in macrophages. PLoS One 7:e40069. doi: 10.1371/journal.pone.0040069

Bai, D. (2016). Structural analysis of key gap junction domains-Lessons from genome data and disease-linked mutants. Semin. Cell Dev. Biol. 50, 74-82. doi: 10.1016/j.semcdb.2015.11.015 stronger therapeutic effects in different human pathological conditions including venous leg ulcers, eye inflammation and trauma, as well as glaucoma (Becker et al., 2016). Future studies will open new horizons to unveil the multiple therapeutic opportunities that are behind the function and regulation of connexin and pannexin-based channels.

\section{AUTHOR CONTRIBUTIONS}

RG-G, VCL and JAO: conceived and designed the major ideas developed in the manuscript, reviewed the literature and designed the tables and figures. JAO: wrote and edited the manuscript. All authors read and approved the final manuscript.

\section{FUNDING}

This work was supported by Fondo Nacional de Desarrollo Científico y Tecnológico (FONDECYT) grants 11121133 (to JAO) and 1160710 (to JAO) and the Comisión Nacional de Investigación Científica y Tecnológica (CONICYT) and Programa de Investigación Asociativa (PIA) Grant Anillo de Ciencia y Tecnología ACT1411 (to JAO).

Bao, L., Locovei, S., and Dahl, G. (2004). Pannexin membrane channels are mechanosensitive conduits for ATP. FEBS Lett. 572, 65-68. doi: 10.1016/j. febslet.2004.07.009

Baroja-Mazo, A., Barberà-Cremades, M., and Pelegrín, P. (2013). The participation of plasma membrane hemichannels to purinergic signaling. Biochim. Biophys. Acta 1828, 79-93. doi: 10.1016/j.bbamem.2012.01.002

Becker, D. L., Phillips, A. R., Duft, B. J., Kim, Y., and Green, C. R. (2016). Translating connexin biology into therapeutics. Semin. Cell Dev. Biol. 50, 49-58. doi: 10.1016/j.semcdb.2015.12.009

Bennett, M. V., Barrio, L. C., Bargiello, T. A., Spray, D. C., Hertzberg, E., and Sáez, J. C. (1991). Gap junctions: new tools, new answers, new questions. Neuron 6, 305-320. doi: 10.1016/0896-6273(91)90241-q

Bernier, L. P., Ase, A. R., Boué-Grabot, E., and Séguéla, P. (2012). P2X4 receptor channels form large noncytolytic pores in resting and activated microglia. Glia 60, 728-737. doi: 10.1002/glia.22301

Bianchi, M. E. (2007). DAMPs, PAMPs and alarmins: all we need to know about danger. J. Leukoc. Biol. 81, 1-5. doi: 10.1189/jlb.0306164

Block, M. L., Zecca, L., and Hong, J. S. (2007). Microglia-mediated neurotoxicity: uncovering the molecular mechanisms. Nat. Rev. Neurosci. 8, 57-69. doi: 10. 1038/nrn2038

Bond, S. R., and Naus, C. C. (2014). The pannexins: past and present. Front. Physiol. 5:58. doi: 10.3389/fphys.2014.00058

Bosch, M., and Kielian, T. (2014). Hemichannels in neurodegenerative diseases: is there a link to pathology? Front. Cell. Neurosci. 8:242. doi: 10.3389/fncel.2014. 00242

Braet, K., Vandamme, W., Martin, P. E., Evans, W. H., and Leybaert, L. (2003). Photoliberating inositol-1,4,5-trisphosphate triggers ATP release that is blocked by the connexin mimetic peptide gap 26. Cell Calcium 33, 37-48. doi: 10.1016/s0143-4160(02)00180-X

Bruzzone, R., Barbe, M. T., Jakob, N. J., and Monyer, H. (2005). Pharmacological properties of homomeric and heteromeric pannexin hemichannels expressed in Xenopus oocytes. J. Neurochem. 92, 1033-1043. doi: 10.1111/j.1471-4159.2004. 02947.x

Bruzzone, S., Guida, L., Zocchi, E., Franco, L., and De Flora, A. (2001). Connexin 43 hemi channels mediate $\mathrm{Ca}^{2+}$-regulated transmembrane $\mathrm{NAD}^{+}$fluxes in intact cells. FASEB J. 15, 10-12. doi: 10.1096/fj.00-0566fje

Bruzzone, R., Hormuzdi, S. G., Barbe, M. T., Herb, A., and Monyer, H. (2003). Pannexins, a family of gap junction proteins expressed in brain. Proc. Natl. Acad. Sci. U S A 100, 13644-13649. doi: 10.1073/pnas.2233464100 
Bugiani, M., Al Shahwan, S., Lamantea, E., Bizzi, A., Bakhsh, E., Moroni, I., et al. (2006). GJA12 mutations in children with recessive hypomyelinating leukoencephalopathy. Neurology 67, 273-279. doi: 10.1212/01.wnl.0000223832. 66286.e4

Burm, S. M., Zuiderwijk-Sick, E. A., T Jong, A. E., Van Der Putten, C., Veth, J., Kondova, I., et al. (2015). Inflammasome-induced IL-1 $\beta$ secretion in microglia is characterized by delayed kinetics and is only partially dependent on inflammatory caspases. J. Neurosci. 35, 678-687. doi: 10.1523/jneurosci.251014.2015

Burra, S., Nicolella, D. P., Francis, W. L., Freitas, C. J., Mueschke, N. J., Poole, K., et al. (2010). Dendritic processes of osteocytes are mechanotransducers that induce the opening of hemichannels. Proc. Natl. Acad. Sci. U S A 107, 13648-13653. doi: 10.1073/pnas.1009382107

Carracedo, A., Geelen, M. J., Diez, M., Hanada, K., Guzmán, M., and Velasco, G. (2004). Ceramide sensitizes astrocytes to oxidative stress: protective role of cannabinoids. Biochem. J. 380, 435-440. doi: 10.1042/bj20031714

Cepeda, C., Chang, J. W., Owens, G. C., Huynh, M. N., Chen, J. Y., Tran, C., et al. (2015). In Rasmussen encephalitis, hemichannels associated with microglial activation are linked to cortical pyramidal neuron coupling: a possible mechanism for cellular hyperexcitability. CNS Neurosci. Ther. 21, 152-163. doi: $10.1111 /$ cns.12352

Chahrour, M., and Zoghbi, H. Y. (2007). The story of Rett syndrome: from clinic to neurobiology. Neuron 56, 422-437. doi: 10.1016/j.neuron.2007.10.001

Chakfe, Y., Seguin, R., Antel, J. P., Morissette, C., Malo, D., Henderson, D., et al. (2002). ADP and AMP induce interleukin-1beta release from microglial cells through activation of ATP-primed $\mathrm{P}_{2} \mathrm{X}_{7}$ receptor channels. J. Neurosci. 22, 3061-3069.

Chao, C. C., Hu, S., and Peterson, P. K. (1995). Modulation of human microglial cell superoxide production by cytokines. J. Leukoc. Biol. 58, 65-70.

Chaumont, S., and Khakh, B. S. (2008). Patch-clamp coordinated spectroscopy shows P2X2 receptor permeability dynamics require cytosolic domain rearrangements but not Panx-1 channels. Proc. Natl. Acad. Sci. U S A 105, 12063-12068. doi: 10.1073/pnas.0803008105

Cherian, P. P., Siller-Jackson, A. J., Gu, S., Wang, X., Bonewald, L. F., Sprague, E., et al. (2005). Mechanical strain opens connexin 43 hemichannels in osteocytes: a novel mechanism for the release of prostaglandin. Mol. Biol. Cell 16, 3100-3106. doi: 10.1091/mbc.e04-10-0912

Chever, O., Lee, C. Y., and Rouach, N. (2014). Astroglial connexin43 hemichannels tune basal excitatory synaptic transmission. J. Neurosci. 34, 11228-11232. doi: 10.1523/jneurosci.0015-14.2014

Contreras, J. E., Sáez, J. C., Bukauskas, F. F., and Bennett, M. V. (2003). Gating and regulation of connexin 43 (Cx43) hemichannels. Proc. Natl. Acad. Sci. U S A 100, 11388-11393. doi: 10.1073/pnas.1434298100

Corvalán, L. A., Araya, R., Brañes, M. C., Sáez, P. J., Kalergis, A. M., Tobar, J. A., et al. (2007). Injury of skeletal muscle and specific cytokines induce the expression of gap junction channels in mouse dendritic cells. J. Cell. Physiol. 211, 649-660. doi: 10.1002/jcp.20971

Cotrina, M. L., Lin, J. H., Alves-Rodrigues, A., Liu, S., Li, J., Azmi-Ghadimi, H., et al. (1998). Connexins regulate calcium signaling by controlling ATP release. Proc. Natl. Acad. Sci. U S A 95, 15735-15740. doi: 10.1073/pnas.95.26.15735

Cotrina, M. L., Lin, J. H., and Nedergaard, M. (2008). Adhesive properties of connexin hemichannels. Glia 56, 1791-1798. doi: 10.1002/glia.20728

Dahl, G. (2015). ATP release through pannexon channels. Philos. Trans. R. Soc. Lond. B Biol. Sci. 370:20140191. doi: 10.1098/rstb.2014.0191

Davalos, D., Grutzendler, J., Yang, G., Kim, J. V., Zuo, Y., Jung, S., et al. (2005). ATP mediates rapid microglial response to local brain injury in vivo. Nat. Neurosci. 8, 752-758. doi: 10.1038/nn1472

De Bock, M., Culot, M., Wang, N., Bol, M., Decrock, E., De Vuyst, E., et al. (2011). Connexin channels provide a target to manipulate brain endothelial calcium dynamics and blood-brain barrier permeability. J. Cereb. Blood Flow Metab. 31, 1942-1957. doi: 10.1038/jcbfm.2011.86

De Bock, M., Wang, N., Bol, M., Decrock, E., Ponsaerts, R., Bultynck, G., et al. (2012). Connexin 43 hemichannels contribute to cytoplasmic $\mathrm{Ca}^{2+}$ oscillations by providing a bimodal $\mathrm{Ca}^{2+}$-dependent $\mathrm{Ca}^{2+}$ entry pathway. J. Biol. Chem. 287, 12250-12266. doi: 10.1074/jbc.m111.299610

Decrock, E., De Bock, M., Wang, N., Bultynck, G., Giaume, C., Naus, C. C., et al. (2015). Connexin and pannexin signaling pathways, an architectural blueprint for CNS physiology and pathology? Cell. Mol. Life Sci. 72, 2823-2851. doi: 10. 1007/s00018-015-1962-7
Deitmer, J. W., Rose, C. R., Munsch, T., Schmidt, J., Nett, W., Schneider, H. P., et al. (1999). Leech giant glial cell: functional role in a simple nervous system. Glia 28, 175-182. doi: 10.1002/(sici)1098-1136(199912)28:3<175::aid-glia1>3. 0. co;2-7

De Vuyst, E., Wang, N., Decrock, E., De Bock, M., Vinken, M., Van Moorhem, M., et al. (2009). $\mathrm{Ca}^{2+}$ regulation of connexin 43 hemichannels in C6 glioma and glial cells. Cell Calcium 46, 176-187. doi: 10.1016/j.ceca.2009. 07.002

D’hondt, C., Ponsaerts, R., De Smedt, H., Bultynck, G., and Himpens, B. (2009). Pannexins, distant relatives of the connexin family with specific cellular functions? Bioessays 31, 953-974. doi: 10.1002/bies.200800236

Dobrenis, K., Chang, H. Y., Pina-Benabou, M. H., Woodroffe, A., Lee, S. C., Rozental, R., et al. (2005). Human and mouse microglia express connexin36 and functional gap junctions are formed between rodent microglia and neurons. J. Neurosci. Res. 82, 306-315. doi: 10.1002/jnr.20650

Domercq, M., Vázquez-Villoldo, N., and Matute, C. (2013). Neurotransmitter signaling in the pathophysiology of microglia. Front. Cell. Neurosci. 7:49. doi: $10.3389 /$ fncel.2013.00049

Elgueta, R., Tobar, J. A., Shoji, K. F., De Calisto, J., Kalergis, A. M., Bono, M. R., et al. (2009). Gap junctions at the dendritic cell-T cell interface are key elements for antigen-dependent T cell activation. J. Immunol. 183, 277-284. doi: 10. 4049/jimmunol.0801854

Eugenin, E. A., Basilio, D., Sáez, J. C., Orellana, J. A., Raine, C. S., Bukauskas, F., et al. (2012). The role of gap junction channels during physiologic and pathologic conditions of the human central nervous system. J. Neuroimmune Pharmacol. 7, 499-518. doi: 10.1007/s11481-012-9352-5

Eugenín, E. A., Eckardt, D., Theis, M., Willecke, K., Bennett, M. V., and Saez, J. C. (2001). Microglia at brain stab wounds express connexin 43 and in vitro form functional gap junctions after treatment with interferon-gamma and tumor necrosis factor-alpha. Proc. Natl. Acad. Sci. U S A 98, 4190-4195. doi: 10. 1073/pnas.051634298

Ey, B., Eyking, A., Gerken, G., Podolsky, D. K., and Cario, E. (2009). TLR2 mediates gap junctional intercellular communication through connexin-43 in intestinal epithelial barrier injury. J. Biol. Chem. 284, 22332-22343. doi: 10. 1074/jbc.m901619200

Färber, K., and Kettenmann, H. (2006). Functional role of calcium signals for microglial function. Glia 54, 656-665. doi: 10.1002/glia.20412

Faustmann, P. M., Haase, C. G., Romberg, S., Hinkerohe, D., Szlachta, D., Smikalla, D., et al. (2003). Microglia activation influences dye coupling and Cx43 expression of the astrocytic network. Glia 42, 101-108. doi: 10.1002/glia. 10141

Ferrari, D., Villalba, M., Chiozzi, P., Falzoni, S., Ricciardi-Castagnoli, P., and Di Virgilio, F. (1996). Mouse microglial cells express a plasma membrane pore gated by extracellular ATP. J. Immunol. 156, 1531-1539.

Fields, R. D., and Burnstock, G. (2006). Purinergic signalling in neuron-glia interactions. Nat. Rev. Neurosci. 7, 423-436. doi: 10.1038/nrn1928

Fontainhas, A. M., Wang, M., Liang, K. J., Chen, S., Mettu, P., Damani, M., et al. (2011). Microglial morphology and dynamic behavior is regulated by ionotropic glutamatergic and GABAergic neurotransmission. PLoS One 6:e15973. doi: 10.1371/journal.pone.0015973

Frank, M. G., Baratta, M. V., Sprunger, D. B., Watkins, L. R., and Maier, S. F. (2007). Microglia serve as a neuroimmune substrate for stress-induced potentiation of CNS pro-inflammatory cytokine responses. Brain Behav. Immun. 21, 47-59. doi: 10.1016/j.bbi.2006.03.005

Froger, N., Orellana, J. A., Cohen-Salmon, M., Ezan, P., Amigou, E., Sáez, J. C., et al. (2009). Cannabinoids prevent the opposite regulation of astroglial connexin43 hemichannels and gap junction channels induced by proinflammatory treatments. J. Neurochem. 111, 1383-1397. doi: 10.1111/j.14714159.2009.06407.x

Garg, S., Md Syed, M., and Kielian, T. (2005). Staphylococcus aureusderived peptidoglycan induces $\mathrm{Cx} 43$ expression and functional gap junction intercellular communication in microglia. J. Neurochem. 95, 475-483. doi: 10. 1111/j.1471-4159.2005.03384.x

Garré, J. M., Retamal, M. A., Cassina, P., Barbeito, L., Bukauskas, F. F., Sáez, J. C., et al. (2010). FGF-1 induces ATP release from spinal astrocytes in culture and opens pannexin and connexin hemichannels. Proc. Natl. Acad. Sci. U S A 107, 22659-22664. doi: 10.1073/pnas.1013793107

Giaume, C., Fromaget, C., El Aoumari, A., Cordier, J., Glowinski, J., and Gros, D. (1991). Gap junctions in cultured astrocytes: single-channel currents and 
characterization of channel-forming protein. Neuron 6, 133-143. doi: 10. 1016/0896-6273(91)90128-m

Ginhoux, F., Greter, M., Leboeuf, M., Nandi, S., See, P., Gokhan, S., et al. (2010). Fate mapping analysis reveals that adult microglia derive from primitive macrophages. Science 330, 841-845. doi: 10.1126/science.1194637

Gong, X., Cheng, C., and Xia, C. H. (2007). Connexins in lens development and cataractogenesis. J. Membr. Biol. 218, 9-12. doi: 10.1007/s00232-007-9033-0

Goodenough, D. A., and Paul, D. L. (2009). Gap junctions. Cold Spring Harb. Perspect. Biol. 1:a002576. doi: 10.1101/cshperspect.a002576

Grakoui, A., Bromley, S. K., Sumen, C., Davis, M. M., Shaw, A. S., Allen, P. M., et al. (1999). The immunological synapse: a molecular machine controlling $\mathrm{T}$ cell activation. Science 285, 221-227. doi: 10.1126/science.285.5425.221

Guthrie, P. B., Knappenberger, J., Segal, M., Bennett, M. V., Charles, A. C., and Kater, S. B. (1999). ATP released from astrocytes mediates glial calcium waves. J. Neurosci. 19, 520-528.

Hanisch, U. K. (2002). Microglia as a source and target of cytokines. Glia 40, 140-155. doi: 10.1002/glia.10161

Harcha, P. A., Vargas, A., Yi, C., Koulakoff, A. A., Giaume, C., and Sáez, J. C. (2015). Hemichannels are required for amyloid $\beta$-peptide-induced degranulation and are activated in brain mast cells of APPswe/PS1dE9 mice. J. Neurosci. 35, 9526-9538. doi: 10.1523/jneurosci.3686-14.2015

Harris, A. L. (2007). Connexin channel permeability to cytoplasmic molecules. Prog. Biophys. Mol. Biol. 94, 120-143. doi: 10.1016/j.pbiomolbio.2007. 03.011

Higashi, Y., Segawa, S., Matsuo, T., Nakamura, S., Kikkawa, Y., Nishida, K., et al. (2011). Microglial zinc uptake via zinc transporters induces ATP release and the activation of microglia. Glia 59, 1933-1945. doi: 10.1002/glia.21235

Hinkerohe, D., Smikalla, D., Haghikia, A., Heupel, K., Haase, C. G., Dermietzel, R., et al. (2005). Effects of cytokines on microglial phenotypes and astroglial coupling in an inflammatory coculture model. Glia 52, 85-97. doi: 10.1002/glia. 20223

Hinkerohe, D., Smikalla, D., Schoebel, A., Haghikia, A., Zoidl, G., Haase, C. G., et al. (2010). Dexamethasone prevents LPS-induced microglial activation and astroglial impairment in an experimental bacterial meningitis co-culture model. Brain Res. 1329, 45-54. doi: 10.1016/j.brainres.2010.03.012

Honda, S., Sasaki, Y., Ohsawa, K., Imai, Y., Nakamura, Y., Inoue, K., et al. (2001). Extracellular ATP or ADP induce chemotaxis of cultured microglia through Gi/o-coupled P2Y receptors. J. Neurosci. 21, 1975-1982.

Hung, S. C., Choi, C. H., Said-Sadier, N., Johnson, L., Atanasova, K. R., Sellami, H., et al. (2013). $\mathrm{P} 2 \mathrm{X}_{4}$ assembles with $\mathrm{P} 2 \mathrm{X}_{7}$ and pannexin-1 in gingival epithelial cells and modulates ATP-induced reactive oxygen species production and inflammasome activation. PLoS One 8:e70210. doi: 10.1371/journal.pone. 0070210

Iglesias, R., Dahl, G., Qiu, F., Spray, D. C., and Scemes, E. (2009). Pannexin 1: the molecular substrate of astrocyte "hemichannels". J. Neurosci. 29, 7092-7097. doi: 10.1523/jneurosci.6062-08.2009

Iglesias, R., Locovei, S., Roque, A., Alberto, A. P., Dahl, G., Spray, D. C., et al. (2008). P2 $\mathrm{X}_{7}$ receptor-Pannexin1 complex: pharmacology and signaling. Am. J. Physiol. Cell Physiol. 295, C752-C760. doi: 10.1152/ajpcell.00228.2008

Imura, Y., Morizawa, Y., Komatsu, R., Shibata, K., Shinozaki, Y., Kasai, H., et al. (2013). Microglia release ATP by exocytosis. Glia 61, 1320-1330. doi: 10. $1002 /$ glia.22517

Inoue, K. (2002). Microglial activation by purines and pyrimidines. Glia 40, 156-163. doi: 10.1002/glia.10150

Jiang, T., Long, H., Ma, Y., Long, L., Li, Y., Li, F., et al. (2013). Altered expression of pannexin proteins in patients with temporal lobe epilepsy. Mol. Med. Rep. 8, 1801-1806. doi: 10.3892/mmr.2013.1739

Jiang, J. X., and Penuela, S. (2016). Connexin and pannexin channels in cancer. BMC Cell Biol. 17:12. doi: 10.1186/s12860-016-0094-8

Kaneko, Y., Tachikawa, M., Akaogi, R., Fujimoto, K., Ishibashi, M., Uchida, Y., et al. (2015). Contribution of pannexin 1 and connexin 43 hemichannels to extracellular calcium-dependent transport dynamics in human blood-brain barrier endothelial cells. J. Pharmacol. Exp. Ther. 353, 192-200. doi: 10. 1124/jpet.114.220210

Kanneganti, T. D., Lamkanfi, M., Kim, Y. G., Chen, G., Park, J. H., Franchi, L., et al. (2007). Pannexin-1-mediated recognition of bacterial molecules activates the cryopyrin inflammasome independent of Tolllike receptor signaling. Immunity 26, 433-443. doi: 10.1016/j.immuni.2007. 03.008
Kettenmann, H., Hanisch, U. K., Noda, M., and Verkhratsky, A. (2011). Physiology of microglia. Physiol. Rev. 91, 461-553. doi: 10.1152/physrev.00011.2010

Klaassen, L. J., Sun, Z., Steijaert, M. N., Bolte, P., Fahrenfort, I., Sjoerdsma, T., et al. (2011). Synaptic transmission from horizontal cells to cones is impaired by loss of connexin hemichannels. PLoS Biol. 9:e1001107. doi: 10.1371/journal.pbio. 1001107

Kleopa, K. A., Zamba-Papanicolaou, E., Alevra, X., Nicolaou, P., Georgiou, D. M., Hadjisavvas, A., et al. (2006). Phenotypic and cellular expression of two novel connexin 32 mutations causing CMT1X. Neurology 66, 396-402. doi: 10. 1212/01.WNL.0000196479.93722.59

Koizumi, S. (2010). Synchronization of $\mathrm{Ca}^{2+}$ oscillations: involvement of ATP release in astrocytes. FEBS J. 277, 286-292. doi: 10.1111/j.1742-4658.2009. 07438.x

Kuno, R., Wang, J., Kawanokuchi, J., Takeuchi, H., Mizuno, T., and Suzumura, A. (2005). Autocrine activation of microglia by tumor necrosis factor-alpha. J. Neuroimmunol. 162, 89-96. doi: 10.1016/j.jneuroim.2005. 01.015

Lawson, L. J., Perry, V. H., Dri, P., and Gordon, S. (1990). Heterogeneity in the distribution and morphology of microglia in the normal adult mouse brain. Neuroscience 39, 151-170. doi: 10.1016/0306-4522(90)90229-w

Lee, I. H., Lindqvist, E., Kiehn, O., Widenfalk, J., and Olson, L. (2005). Glial and neuronal connexin expression patterns in the rat spinal cord during development and following injury. J. Comp. Neurol. 489, 1-10. doi: 10. 1002/cne.20567

Li, Y., Du, X. F., and Du, J. L. (2013). Resting microglia respond to and regulate neuronal activity in vivo. Commun. Integr. Biol. 6:e24493. doi: 10.4161/cib. 24493

Li, S., Tomić, M., and Stojilkovic, S. S. (2011). Characterization of novel Pannexin 1 isoforms from rat pituitary cells and their association with ATP-gated P2X channels. Gen. Comp. Endocrinol. 174, 202-210. doi: 10.1016/j.ygcen.2011. 08.019

Lin, J. H., Lou, N., Kang, N., Takano, T., Hu, F., Han, X., et al. (2008). A central role of connexin 43 in hypoxic preconditioning. J. Neurosci. 28, 681-695. doi: 10. 1523/JNEUROSCI.3827-07.2008

Liu, X., Hashimoto-Torii, K., Torii, M., Ding, C., and Rakic, P. (2010). Gap junctions/hemichannels modulate interkinetic nuclear migration in the forebrain precursors. J. Neurosci. 30, 4197-4209. doi: 10.1523/JNEUROSCI. 4187-09.2010

Liu, J., Hjorth, E., Zhu, M., Calzarossa, C., Samuelsson, E. B., Schultzberg, M., et al. (2013). Interplay between human microglia and neural stem/progenitor cells in an allogeneic co-culture model. J. Cell. Mol. Med. 17, 1434-1443. doi: 10. $1111 / \mathrm{jcmm} .12123$

Liu, X., Sun, L., Torii, M., and Rakic, P. (2012). Connexin 43 controls the multipolar phase of neuronal migration to the cerebral cortex. Proc. Natl. Acad. Sci. U S A 109, 8280-8285. doi: 10.1073/pnas. 1205880109

Liu, W., Tang, Y., and Feng, J. (2011). Cross talk between activation of microglia and astrocytes in pathological conditions in the central nervous system. Life Sci. 89, 141-146. doi: 10.1016/j.lfs.2011.05.011

Locovei, S., Bao, L., and Dahl, G. (2006a). Pannexin 1 in erythrocytes: function without a gap. Proc. Natl. Acad. Sci. U S A 103, 7655-7659. doi: 10.1073/pnas. 0601037103

Locovei, S., Wang, J., and Dahl, G. (2006b). Activation of pannexin 1 channels by ATP through P2Y receptors and by cytoplasmic calcium. FEBS Lett. 580, 239-244. doi: 10.1016/j.febslet.2005.12.004

Locovei, S., Scemes, E., Qiu, F., Spray, D. C., and Dahl, G. (2007). Pannexin1 is part of the pore forming unit of the $\mathrm{P}_{2} \mathrm{X}_{7}$ receptor death complex. FEBS Lett. 581, 483-488. doi: 10.1016/j.febslet.2006.12.056

Lopatáŕ, J., Dale, N., and Frenguelli, B. G. (2015). Pannexin-1-mediated ATP release from area CA3 drives mGlu5-dependent neuronal oscillations. Neuropharmacology 93, 219-228. doi: 10.1016/j.neuropharm.2015.01.014

Ma, Y., Cao, W., Wang, L., Jiang, J., Nie, H., Wang, B., et al. (2014). Basal CD38/cyclic ADP-ribose-dependent signaling mediates ATP release and survival of microglia by modulating connexin 43 hemichannels. Glia 62, 943-955. doi: 10.1002/glia.22651

Maezawa, I., and Jin, L. W. (2010). Rett syndrome microglia damage dendrites and synapses by the elevated release of glutamate. J. Neurosci. 30, 5346-5356. doi: 10.1523/JNEUROSCI.5966-09.2010

Mäkelä, J., Koivuniemi, R., Korhonen, L., and Lindholm, D. (2010). Interferon- $\gamma$ produced by microglia and the neuropeptide PACAP have opposite effects on 
the viability of neural progenitor cells. PLoS One 5:e11091. doi: 10.1371/journal. pone.0011091

Malavasi, F., Deaglio, S., Funaro, A., Ferrero, E., Horenstein, A. L., Ortolan, E., et al. (2008). Evolution and function of the ADP ribosyl cyclase/CD38 gene family in physiology and pathology. Physiol. Rev. 88, 841-886. doi: 10. 1152/physrev.00035.2007

Martínez, A. D., Acuña, R., Figueroa, V., Maripillan, J., and Nicholson, B. (2009). Gap-junction channels dysfunction in deafness and hearing loss. Antioxid. Redox Signal. 11, 309-322. doi: 10.1089/ars.2008.2138

Martínez, A. D., Eugenín, E. A., Brañes, M. C., Bennett, M. V., and Sáez, J. C. (2002). Identification of second messengers that induce expression of functional gap junctions in microglia cultured from newborn rats. Brain Res. 943, 191-201. doi: 10.1016/s0006-8993(02)02621-5

Martino, G., and Pluchino, S. (2006). The therapeutic potential of neural stem cells. Nat. Rev. Neurosci. 7, 395-406. doi: 10.1038/nrn1908

Martinon, F., Burns, K., and Tschopp, J. (2002). The inflammasome: a molecular platform triggering activation of inflammatory caspases and processing of proIL-beta. Mol. Cell 10, 417-426. doi: 10.1016/S1097-2765(02)00599-3

Matsue, H., Yao, J., Matsue, K., Nagasaka, A., Sugiyama, H., Aoki, R., et al. (2006). Gap junction-mediated intercellular communication between dendritic cells (DCs) is required for effective activation of DCs. J. Immunol. 176, 181-190. doi: 10.4049/jimmunol.176.1.181

McClain, J. L., Grubišić, V., Fried, D., Gomez-Suarez, R. A., Leinninger, G. M., Sévigny, J., et al. (2014). $\mathrm{Ca}^{2+}$ responses in enteric glia are mediated by connexin- 43 hemichannels and modulate colonic transit in mice. Gastroenterology 146, 497.e1-507.e1. doi: 10.1053/j.gastro.2013.10.061

Même, W., Calvo, C. F., Froger, N., Ezan, P., Amigou, E., Koulakoff, A., et al. (2006). Proinflammatory cytokines released from microglia inhibit gap junctions in astrocytes: potentiation by $\beta$-amyloid. FASEB J. 20, 494-496. doi: 10.1096/fj.05-4297fje

Mendoza-Naranjo, A., Bouma, G., Pereda, C., Ramírez, M., Webb, K. F., Tittarelli, A., et al. (2011). Functional gap junctions accumulate at the immunological synapse and contribute to T cell activation. J. Immunol. 187, 3121-3132. doi: 10.4049/jimmunol.1100378

Mendoza-Naranjo, A., Saéz, P. J., Johansson, C. C., Ramírez, M., Mandakovic, D., Pereda, C., et al. (2007). Functional gap junctions facilitate melanoma antigen transfer and cross-presentation between human dendritic cells. J. Immunol. 178, 6949-6957. doi: 10.4049/jimmunol.178.11.6949

Minkiewicz, J., de Rivero Vaccari, J. P., and Keane, R. W. (2013). Human astrocytes express a novel NLRP2 inflammasome. Glia 61, 1113-1121. doi: 10.1002/glia. 22499

Moon, Y., Choi, S. Y., Kim, K., Kim, H., and Sun, W. (2010). Expression of connexin 29 and 32 in the penumbra region after traumatic brain injury of mice. Neuroreport 21, 1135-1139. doi: 10.1097/wnr.0b013e32834051c7

Moore, A. R., Zhou, W. L., Sirois, C. L., Belinsky, G. S., Zecevic, N., and Antic, S. D. (2014). Connexin hemichannels contribute to spontaneous electrical activity in the human fetal cortex. Proc. Natl. Acad. Sci. U S A 111, E3919-E3928. doi: 10. 1073/pnas.1405253111

Mosher, K. I., Andres, R. H., Fukuhara, T., Bieri, G., Hasegawa-Moriyama, M., $\mathrm{He}$, Y., et al. (2012). Neural progenitor cells regulate microglia functions and activity. Nat. Neurosci. 15, 1485-1487. doi: 10.1038/nn.3233

Murphy, N., Cowley, T. R., Richardson, J. C., Virley, D., Upton, N., Walter, D., et al. (2012). The neuroprotective effect of a specific $\mathrm{P}_{2} \mathrm{X}_{7}$ receptor antagonist derives from its ability to inhibit assembly of the NLRP3 inflammasome in glial cells. Brain Pathol. 22, 295-306. doi: 10.1111/j.1750-3639.2011.00531.x

Mylvaganam, S., Ramani, M., Krawczyk, M., and Carlen, P. L. (2014). Roles of gap junctions, connexins and pannexins in epilepsy. Front. Physiol. 5:172. doi: 10. 3389/fphys.2014.00172

Nair, A., and Bonneau, R. H. (2006). Stress-induced elevation of glucocorticoids increases microglia proliferation through NMDA receptor activation. J. Neuroimmunol. 171, 72-85. doi: 10.1016/j.jneuroim.2005.09.012

Neijssen, J., Herberts, C., Drijfhout, J. W., Reits, E., Janssen, L., and Neefjes, J. (2005). Cross-presentation by intercellular peptide transfer through gap junctions. Nature 434, 83-88. doi: 10.1038/nature03290

Netea, M. G., Simon, A., van de Veerdonk, F., Kullberg, B. J., van der Meer, J. W., and Joosten, L. A. (2010). IL-1 $\beta$ processing in host defense: beyond the inflammasomes. PLoS Pathog. 6:e1000661. doi: 10.1371/journal.ppat.1000661

Nolte, C., Möller, T., Walter, T., and Kettenmann, H. (1996). Complement 5a controls motility of murine microglial cells in vitro via activation of an inhibitory G-protein and the rearrangement of the actin cytoskeleton. Neuroscience 73, 1091-1107. doi: 10.1016/0306-4522(96)00106-6

Orellana, J. A., Busso, D., Ramirez, G., Campos, M., Rigotti, A., Eugenin, J., et al. (2014). Prenatal nicotine exposure enhances Cx43 and Panx1 unopposed channel activity in brain cells of adult offspring mice fed a high-fat/cholesterol diet. Front. Cell. Neurosci. 8:403. doi: 10.3389/fncel.2014.00403

Orellana, J. A., Froger, N., Ezan, P., Jiang, J. X., Bennett, M. V., Naus, C. C., et al. (2011a). ATP and glutamate released via astroglial connexin 43 hemichannels mediate neuronal death through activation of pannexin 1 hemichannels. J. Neurochem. 118, 826-840. doi: 10.1111/j.1471-4159.2011.07210.x

Orellana, J. A., Shoji, K. F., Abudara, V., Ezan, P., Amigou, E., Saez, P. J., et al. (2011b). Amyloid $\beta$-induced death in neurons involves glial and neuronal hemichannels. J. Neurosci. 31, 4962-4977. doi: 10.1523/JNEUROSCI.641710.2011

Orellana, J. A., Martinez, A. D., and Retamal, M. A. (2013a). Gap junction channels and hemichannels in the CNS: regulation by signaling molecules. Neuropharmacology $\quad 75, \quad 567-582$. doi: 10.1016/j.neuropharm.2013. 02.020

Orellana, J. A., Montero, T. D., and von Bernhardi, R. (2013b). Astrocytes inhibit nitric oxide-dependent $\mathrm{Ca}^{2+}$ dynamics in activated microglia: involvement of ATP released via pannexin 1 channels. Glia 61, 2023-2037. doi: 10.1002/glia. 22573

Orellana, J. A., Moraga-Amaro, R., Diaz-Galarce, R., Rojas, S., Maturana, C. J., Stehberg, J., et al. (2015). Restraint stress increases hemichannel activity in hippocampal glial cells and neurons. Front. Cell. Neurosci. 9:102. doi: 10. 3389/fncel.2015.00102

Orellana, J. A., Sáez, P. J., Cortés-Campos, C., Elizondo, R. J., Shoji, K. F., Contreras-Duarte, S., et al. (2012a). Glucose increases intracellular free $\mathrm{Ca}^{2+}$ in tanycytes via ATP released through connexin 43 hemichannels. Glia 60, 53-68. doi: 10.1002/glia.21246

Orellana, J. A., von Bernhardi, R., Giaume, C., and Saez, J. C. (2012b). Glial hemichannels and their involvement in aging and neurodegenerative diseases. Rev. Neurosci. 23, 163-177. doi: 10.1515/revneuro-2011-0065

Panchin, Y., Kelmanson, I., Matz, M., Lukyanov, K., Usman, N., and Lukyanov, S. (2000). A ubiquitous family of putative gap junction molecules. Curr. Biol. 10, R473-R474. doi: 10.1016/s0960-9822(00)00576-5

Parenti, R., Campisi, A., Vanella, A., and Cicirata, F. (2002). Immunocytochemical and RT-PCR analysis of connexin36 in cultures of mammalian glial cells. Arch. Ital. Biol. 140, 101-108.

Paul, D. L., Ebihara, L., Takemoto, L. J., Swenson, K. I., and Goodenough, D. A. (1991). Connexin46, a novel lens gap junction protein, induces voltage-gated currents in nonjunctional plasma membrane of Xenopus oocytes. J. Cell Biol. 115, 1077-1089. doi: 10.1083/jcb.115.4.1077

Paznekas, W. A., Karczeski, B., Vermeer, S., Lowry, R. B., Delatycki, M., Laurence, F., et al. (2009). GJA1 mutations, variants and connexin 43 dysfunction as it relates to the oculodentodigital dysplasia phenotype. Hum. Mutat. 30, 724-733. doi: 10.1002/humu.20958

Pelegrin, P., and Surprenant, A. (2006). Pannexin-1 mediates large pore formation and interleukin- $1 \beta$ release by the ATP-gated $\mathrm{P} 2 \mathrm{X}_{7}$ receptor. EMBO J. 25, 5071-5082. doi: 10.1038/sj.emboj.7601378

Pelegrin, P., and Surprenant, A. (2007). Pannexin-1 couples to maitotoxin- and nigericin-induced interleukin-1beta release through a dye uptake-independent pathway. J. Biol. Chem. 282, 2386-2394. doi: 10.1074/jbc.m610351200

Pelegrin, P., and Surprenant, A. (2009). The P2X 7 receptor-pannexin connection to dye uptake and IL-1 $\beta$ release. Purinergic Signal. 5, 129-137. doi: 10. 1007/s11302-009-9141-7

Penuela, S., Harland, L., Simek, J., and Laird, D. W. (2014). Pannexin channels and their links to human disease. Biochem. J. 461, 371-381. doi: 10.1042/bj20140447

Peracchia, C. (2004). Chemical gating of gap junction channels; roles of calcium, $\mathrm{pH}$ and calmodulin. Biochim. Biophys. Acta 1662, 61-80. doi: 10.1016/j. bbamem.2003.10.020

Poornima, V., Madhupriya, M., Kootar, S., Sujatha, G., Kumar, A., and Bera, A. K. (2012). P2X 7 receptor-pannexin 1 hemichannel association: effect of extracellular calcium on membrane permeabilization. J. Mol. Neurosci. 46, 585-594. doi: 10.1007/s12031-011-9646-8

Prochnow, N., Abdulazim, A., Kurtenbach, S., Wildförster, V., Dvoriantchikova, G., Hanske, J., et al. (2012). Pannexin1 stabilizes synaptic plasticity and is needed for learning. PLoS One 7:e51767. doi: 10.1371/journal. pone. 0051767 
Qiu, F., and Dahl, G. (2009). A permeant regulating its permeation pore: inhibition of pannexin 1 channels by ATP. Am. J. Physiol. Cell Physiol. 296, C250-C255. doi: 10.1152 /ajpcell.00433.2008

Ransohoff, R. M., and El Khoury, J. (2015). Microglia in health and disease. Cold Spring Harb. Perspect. Biol. 8:a020560. doi: 10.1101/cshperspect.a020560

Retamal, M. A., Cortés, C. J., Reuss, L., Bennett, M. V., and Sáez, J. C. (2006). S-nitrosylation and permeation through connexin 43 hemichannels in astrocytes: induction by oxidant stress and reversal by reducing agents. Proc. Natl. Acad. Sci. U S A 103, 4475-4480. doi: 10.1073/pnas.05111 18103

Retamal, M. A., Froger, N., Palacios-Prado, N., Ezan, P., Sáez, P. J., Sáez, J. C., et al. (2007a). Cx43 hemichannels and gap junction channels in astrocytes are regulated oppositely by proinflammatory cytokines released from activated microglia. J. Neurosci. 27, 13781-13792. doi: 10.1523/JNEUROSCI.2042-07. 2007

Retamal, M. A., Schalper, K. A., Shoji, K. F., Bennett, M. V., and Saez, J. C. (2007b). Opening of connexin 43 hemichannels is increased by lowering intracellular redox potential. Proc. Natl. Acad. Sci. U S A 104, 8322-8327. doi: 10.1073/pnas. 0702456104

Retamal, M. A., Reyes, E. P., García, I. E., Pinto, B., Martínez, A. D., and Gonzélez, C. (2015). Diseases associated with leaky hemichannels. Front. Cell. Neurosci. 9:267. doi: 10.3389/fncel.2015.00267

Richter, N., Wendt, S., Georgieva, P. B., Hambardzumyan, D., Nolte, C., and Kettenmann, H. (2014). Glioma-associated microglia and macrophages/monocytes display distinct electrophysiological properties and do not communicate via gap junctions. Neurosci. Lett. 583, 130-135. doi: 10.1016/j.neulet.2014.09.035

Rigato, C., Swinnen, N., Buckinx, R., Couillin, I., Mangin, J. M., Rigo, J. M., et al. (2012). Microglia proliferation is controlled by $\mathrm{P} 2 \mathrm{X}_{7}$ receptors in a Pannexin-1independent manner during early embryonic spinal cord invasion. J. Neurosci. 32, 11559-11573. doi: 10.1523/JNEUROSCI.1042-12.2012

Romanov, R. A., Rogachevskaja, O. A., Bystrova, M. F., Jiang, P., Margolskee, R. F., and Kolesnikov, S. S. (2007). Afferent neurotransmission mediated by hemichannels in mammalian taste cells. EMBO J. 26, 657-667. doi: 10.1038/sj. emboj.7601526

Rouach, N., Calvo, C. F., Glowinski, J., and Giaume, C. (2002). Brain macrophages inhibit gap junctional communication and downregulate connexin 43 expression in cultured astrocytes. Eur. J. Neurosci. 15, 403-407. doi: 10.1046/j. 0953-816x.2001.01868.x

Roux, L., Madar, A., Lacroix, M. M., Yi, C., Benchenane, K., and Giaume, C. (2015). Astroglial connexin 43 hemichannels modulate olfactory bulb slow oscillations. J. Neurosci. 35, 15339-15352. doi: 10.1523/JNEUROSCI.0861-15.2015

Rovegno, M., Soto, P. A., Sáez, P. J., Naus, C. C., Sáez, J. C., and von Bernhardi, R. (2015). Connexin 43 hemichannels mediate secondary cellular damage spread from the trauma zone to distal zones in astrocyte monolayers. Glia 63, 1185-1199. doi: 10.1002/glia.22808

Sáez, J. C., Berthoud, V. M., Branes, M. C., Martinez, A. D., and Beyer, E. C. (2003). Plasma membrane channels formed by connexins: their regulation and functions. Physiol. Rev. 83, 1359-1400. doi: 10.1152/physrev.00007.2003

Sáez, J. C., and Leybaert, L. (2014). Hunting for connexin hemichannels. FEBS Lett. 588, 1205-1211. doi: 10.1016/j.febslet.2014.03.004

Sáez, P. J., Shoji, K. F., Retamal, M. A., Harcha, P. A., Ramírez, G., Jiang, J. X., et al. (2013). ATP is required and advances cytokine-induced gap junction formation in microglia in vitro. Mediators Inflamm. 2013:216402. doi: 10. $1155 / 2013 / 216402$

Salter, M. W., and Beggs, S. (2014). Sublime microglia: expanding roles for the guardians of the CNS. Cell 158, 15-24. doi: 10.1016/j.cell.2014. 06.008

Samuels, S. E., Lipitz, J. B., Dahl, G., and Muller, K. J. (2010). Neuroglial ATP release through innexin channels controls microglial cell movement to a nerve injury. J. Gen. Physiol. 136, 425-442. doi: 10.1085/jgp.2010 10476

Samuels, S. E., Lipitz, J. B., Wang, J., Dahl, G., and Muller, K. J. (2013). Arachidonic acid closes innexin/pannexin channels and thereby inhibits microglia cell movement to a nerve injury. Dev. Neurobiol. 73, 621-631. doi: 10.1002/dneu. 22088

Sarrouilhe, D., Dejean, C., and Mesnil, M. (2014). Involvement of gap junction channels in the pathophysiology of migraine with aura. Front. Physiol. 5:78. doi: $10.3389 /$ fphys.2014.00078
Schafer, D. P., Lehrman, E. K., and Stevens, B. (2013). The "quad-partite" synapse: microglia-synapse interactions in the developing and mature CNS. Glia 61, 24-36. doi: 10.1002/glia.22389

Schipke, C. G., Boucsein, C., Ohlemeyer, C., Kirchhoff, F., and Kettenmann, H. (2002). Astrocyte $\mathrm{Ca}^{2+}$ waves trigger responses in microglial cells in brain slices. FASEB J. 16, 255-257. doi: 10.1096/fj.01-0514fje

Schock, S. C., Leblanc, D., Hakim, A. M., and Thompson, C. S. (2008). ATP release by way of connexin 36 hemichannels mediates ischemic tolerance in vitro. Biochem. Biophys. Res. Commun. 368, 138-144. doi: 10.1016/j.bbrc.2008.01.054

Seil, M., El Ouaaliti, M., Fontanils, U., Etxebarria, I. G., Pochet, S., Dal Moro, G., et al. (2010). Ivermectin-dependent release of IL-1beta in response to ATP by peritoneal macrophages from $\mathrm{P} 2 \mathrm{X}_{7}-\mathrm{KO}$ mice. Purinergic Signal. 6, 405-416. doi: 10.1007/s11302-010-9205-8

Seo, D. R., Kim, S. Y., Kim, K. Y., Lee, H. G., Moon, J. H., Lee, J. S., et al. (2008). Cross talk between P2 purinergic receptors modulates extracellular ATP-mediated interleukin-10 production in rat microglial cells. Exp. Mol. Med. 40, 19-26. doi: 10.3858/emm.2008.40.1.19

Severs, N. J., Bruce, A. F., Dupont, E., and Rothery, S. (2008). Remodelling of gap junctions and connexin expression in diseased myocardium. Cardiovasc. Res. 80, 9-19. doi: $10.1093 / \mathrm{cvr} / \mathrm{cvn} 133$

Shaikh, S. B., Uy, B., Perera, A., and Nicholson, L. F. (2012). AGEs-RAGE mediated up-regulation of connexin 43 in activated human microglial CHME-5 cells. Neurochem. Int. 60, 640-651. doi: 10.1016/j.neuint.2012.02.023

Shestopalov, V. I., and Slepak, V. Z. (2014). Molecular pathways of pannexin1mediated neurotoxicity. Front. Physiol. 5:23. doi: 10.3389/fphys.2014.00023

Shigemoto-Mogami, Y., Hoshikawa, K., Goldman, J. E., Sekino, Y., and Sato, K. (2014). Microglia enhance neurogenesis and oligodendrogenesis in the early postnatal subventricular zone. J. Neurosci. 34, 2231-2243. doi: 10. 1523/JNEUROSCI.1619-13.2014

Shijie, J., Takeuchi, H., Yawata, I., Harada, Y., Sonobe, Y., Doi, Y., et al. (2009). Blockade of glutamate release from microglia attenuates experimental autoimmune encephalomyelitis in mice. Tohoku J. Exp. Med. 217, 87-92. doi: $10.1620 /$ tjem.217.87

Silverman, W. R., de Rivero Vaccari, J. P., Locovei, S., Qiu, F., Carlsson, S. K., Scemes, E., et al. (2009). The pannexin 1 channel activates the inflammasome in neurons and astrocytes. J. Biol. Chem. 284, 18143-18151. doi: 10.1074/jbc. M109.004804

Söhl, G., Maxeiner, S., and Willecke, K. (2005). Expression and functions of neuronal gap junctions. Nat. Rev. Neurosci. 6, 191-200. doi: 10.1038/nrn1627

Song, E. K., Rah, S. Y., Lee, Y. R., Yoo, C. H., Kim, Y. R., Yeom, J. H., et al. (2011). Connexin-43 hemichannels mediate cyclic ADP-ribose generation and its $\mathrm{Ca}^{2+}$-mobilizing activity by $\mathrm{NAD}^{+} /$cyclic ADP-ribose transport. J. Biol. Chem. 286, 44480-44490. doi: 10.1074/jbc.M111.307645

Sorge, R. E., Trang, T., Dorfman, R., Smith, S. B., Beggs, S., Ritchie, J., et al. (2012). Genetically determined $\mathrm{P} 2 \mathrm{X}_{7}$ receptor pore formation regulates variability in chronic pain sensitivity. Nat. Med. 18, 595-599. doi: 10.1038/nm.2710

Sosinsky, G. E., Boassa, D., Dermietzel, R., Duffy, H. S., Laird, D. W., MacVicar, B., et al. (2011). Pannexin channels are not gap junction hemichannels. Channels (Austin) 5, 193-197. doi: 10.4161/chan.5.3.15765

Srinivas, M., Rozental, R., Kojima, T., Dermietzel, R., Mehler, M., Condorelli, D. F., et al. (1999). Functional properties of channels formed by the neuronal gap junction protein connexin36. J. Neurosci. 19, 9848-9855.

Stehberg, J., Moraga-Amaro, R., Salazar, C., Becerra, A., Echeverría, C., Orellana, J. A., et al. (2012). Release of gliotransmitters through astroglial connexin 43 hemichannels is necessary for fear memory consolidation in the basolateral amygdala. FASEB J. 26, 3649-3657. doi: 10.1096/fj.11198416

Stout, C. E., Costantin, J. L., Naus, C. C. G., and Charles, A. C. (2002). Intercellular calcium signaling in astrocytes via ATP release through connexin hemichannels. J. Biol. Chem. 277, 10482-10488. doi: 10.1074/jbc.m109 902200

Streit, W. J. (2001). Microglia and macrophages in the developing CNS. Neurotoxicology 22, 619-624. doi: 10.1016/s0161-813x(01)00033-x

Suadicani, S. O., Iglesias, R., Wang, J., Dahl, G., Spray, D. C., and Scemes, E. (2012). ATP signaling is deficient in cultured Pannexin1-null mouse astrocytes. Glia 60, 1106-1116. doi: 10.1002/glia.22338

Takeuchi, H., Jin, S., Suzuki, H., Doi, Y., Liang, J., Kawanokuchi, J., et al. (2008). Blockade of microglial glutamate release protects against ischemic brain injury. Exp. Neurol. 214, 144-146. doi: 10.1016/j.expneurol.2008.08.001 
Takeuchi, H., Jin, S., Wang, J., Zhang, G., Kawanokuchi, J., Kuno, R., et al. (2006). Tumor necrosis factor-alpha induces neurotoxicity via glutamate release from hemichannels of activated microglia in an autocrine manner. J. Biol. Chem. 281, 21362-21368. doi: 10.1074/jbc.m600504200

Takeuchi, H., Mizoguchi, H., Doi, Y., Jin, S., Noda, M., Liang, J., et al. (2011). Blockade of gap junction hemichannel suppresses disease progression in mouse models of amyotrophic lateral sclerosis and Alzheimer's disease. PLoS One 6:e21108. doi: 10.1371/journal.pone.0021108

Takeuchi, H., and Suzumura, A. (2014). Gap junctions and hemichannels composed of connexins: potential therapeutic targets for neurodegenerative diseases. Front. Cell. Neurosci. 8:189. doi: 10.3389/fncel.2014. 00189

Talaverón, R., Fernández, P., Escamilla, R., Pastor, A. M., Matarredona, E. R., and Sáez, J. C. (2015). Neural progenitor cells isolated from the subventricular zone present hemichannel activity and form functional gap junctions with glial cells. Front. Cell. Neurosci. 9:411. doi: 10.3389/fncel.2015.00411

Talaverón, R., Matarredona, E. R., de la Cruz, R. R., Macías, D., Gálvez, V., and Pastor, A. M. (2014). Implanted neural progenitor cells regulate glial reaction to brain injury and establish gap junctions with host glial cells. Glia 62, 623-638. doi: 10.1002/glia.22630

Terada, K., Yamada, J., Hayashi, Y., Wu, Z., Uchiyama, Y., Peters, C., et al. (2010). Involvement of cathepsin B in the processing and secretion of interleukin- $1 \beta$ in chromogranin A-stimulated microglia. Glia 58, 114-124. doi: 10.1002/glia. 20906

Teubner, B., Degen, J., Söhl, G., Güldenagel, M., Bukauskas, F. F., Trexler, E. B., et al. (2000). Functional expression of the murine connexin 36 gene coding for a neuron-specific gap junctional protein. J. Membr. Biol. 176, 249-262. doi: 10. 1007/s002320001094

Tong, D., Li, T. Y., Naus, K. E., Bai, D., and Kidder, G. M. (2007). In vivo analysis of undocked connexin43 gap junction hemichannels in ovarian granulosa cells. J. Cell Sci. 120, 4016-4024. doi: 10.1242/jcs.011775

van Kasteren, S. I., Overkleeft, H., Ovaa, H., and Neefjes, J. (2014). Chemical biology of antigen presentation by MHC molecules. Curr. Opin. Immunol. 26, 21-31. doi: 10.1016/j.coi.2013.10.005

Verderio, C., and Matteoli, M. (2001). ATP mediates calcium signaling between astrocytes and microglial cells: modulation by IFN-gamma. J. Immunol. 166, 6383-6391. doi: 10.4049/jimmunol.166.10.6383

Waisman, A., Ginhoux, F., Greter, M., and Bruttger, J. (2015). Homeostasis of microglia in the adult brain: review of novel microglia depletion systems. Trends Immunol. 36, 625-636. doi: 10.1016/j.it.2015. 08.005
Wake, H., Moorhouse, A. J., Miyamoto, A., and Nabekura, J. (2013). Microglia: actively surveying and shaping neuronal circuit structure and function. Trends Neurosci. 36, 209-217. doi: 10.1016/j.tins.2012.11.007

Wang, N., De Bock, M., Antoons, G., Gadicherla, A. K., Bol, M., Decrock, E., et al. (2012). Connexin mimetic peptides inhibit Cx43 hemichannel opening triggered by voltage and intracellular $\mathrm{Ca}^{2+}$ elevation. Basic Res. Cardiol. 107:304. doi: 10.1007/s00395-012-0304-2

Wang, N., De Bock, M., Decrock, E., Bol, M., Gadicherla, A., Vinken, M., et al. (2013). Paracrine signaling through plasma membrane hemichannels. Biochim. Biophys. Acta 1828, 35-50. doi: 10.1016/j.bbamem.2012.07.002

Wasseff, S. K., and Scherer, S. S. (2014). Activated microglia do not form functional gap junctions in vivo. J. Neuroimmunol. 269, 90-93. doi: 10.1016/j.jneuroim. 2014.02.005

Wenker, I. C., Sobrinho, C. R., Takakura, A. C., Moreira, T. S., and Mulkey, D. K. (2012). Regulation of ventral surface $\mathrm{CO} 2 / \mathrm{H}+$-sensitive neurons by purinergic signalling. J. Physiol. 590, 2137-2150. doi: 10.1113/jphysiol.2012.229666

Wicki-Stordeur, L. E., Dzugalo, A. D., Swansburg, R. M., Suits, J. M., and Swayne, L. A. (2012). Pannexin 1 regulates postnatal neural stem and progenitor cell proliferation. Neural Dev. 7:11. doi: 10.1186/1749-8104-7-11

Wu, Y., Dissing-Olesen, L., MacVicar, B. A., and Stevens, B. (2015). Microglia: dynamic mediators of synapse development and plasticity. Trends Immunol. 36, 605-613. doi: 10.1016/j.it.2015.08.008

Ye, Z.-C., Wyeth, M. S., Baltan-Tekkok, S., and Ransom, B. R. (2003). Functional hemichannels in astrocytes: a novel mechanism of glutamate release. J. Neurosci. 23, 3588-3596.

Zhang, M., Piskuric, N. A., Vollmer, C., and Nurse, C. A. (2012). P2Y2 receptor activation opens pannexin-1 channels in rat carotid body type II cells: potential role in amplifying the neurotransmitter ATP. J. Physiol. 590, 4335-4350. doi: 10.1113/jphysiol.2012.236265

Conflict of Interest Statement: The authors declare that the research was conducted in the absence of any commercial or financial relationships that could be construed as a potential conflict of interest.

Copyright (c) 2016 Gajardo-Gómez, Labra and Orellana. This is an open-access article distributed under the terms of the Creative Commons Attribution License (CC BY). The use, distribution and reproduction in other forums is permitted, provided the original author(s) or licensor are credited and that the original publication in this journal is cited, in accordance with accepted academic practice. No use, distribution or reproduction is permitted which does not comply with these terms. 